\title{
Toxicological and Pathological Applications of Proliferating Cell Nuclear Antigen (PCNA), A Novel Endogenous Marker for Cell Proliferation
}

\author{
Daniel R. Dietrich \\ Institute of Toxicology, Swiss Federal Institute of Technology and University of Zürich, $\mathrm{CH}-8603$ \\ Schwerzenbach, Switzerland
}

\begin{abstract}
A major stimulus to study cell proliferation, particularly in rodent carcinogenicity assays and human tumors, has been the belief that the quantification of this fundamental biological process will provide the toxicologist and pathologist with objective data allowing a better understanding of the mechanisms involved in the toxicity and/or carcinogenicity of certain compounds as well as guiding more effective management of patients afflicted with neoplasia. Among the markers used for cell proliferation measurement, PCNA has recently gained much attention and holds much promise as it is intricately involved in the cell replication processes. It not only could allow measurement of the replication rates without necessitating pretreatment of the animal/tissue in prospective studies, but also would allow retrospective assessment of the proliferative rates in archival tissues due to the conservation of this marker in fixed and paraffin-embedded tissues. Finally, knowledge of the function of PCNA in the cell cycle and its regulation by other factors may help us understand the advantages and limitations of PCNA as a cell proliferation marker in its application in toxicology and as a prognostic marker in human tumors.
\end{abstract}

KEY WORDS: PCNA, retrospective, cell cycle, pathology, immunohistochemistry, DNA synthesis, DNA excision repair, prognostic marker.

\section{INTRODUCTION}

The fundamental biological process of cell division, and thus of cell proliferation, has been investigated from various viewpoints for a number of years. In the course of these investigations, numerous proteins intricately involved in the mechanism of cell division have been discovered. Among these, the proliferating cell nuclear antigen (PCNA/cyclin) has been most intensively investigated not only due to its role in DNA synthesis and DNA repair mechanisms, but also as a result of its use as a cell proliferation marker and particularly as a prognostic tool in surgical pathology. Indeed, the existence of an endogenous cell proliferation marker that is preserved during tissue processing for pathological studies makes it tempting for toxicologists and pathologists to "go back" to studies that were completed some time in the past and measure retrospectively the cell proliferation rates resulting from the respective treatment regimens used in a particular study. However, the mere fact that this cell proliferation marker is a nuclear protein, the expression of which could be regulated by numerous factors and which may be involved in more than one mechanism of cell cycle control, should raise some doubt whether the "cell proliferation rates" measured via immunohistochemistry or flow cytometry can be taken as such without additional knowledge of the effects of the compound in question on the expression lev- 
els of PCNA or its regulating factors. Furthermore, although many lesions/tumors were shown to appear in conjunction with oncogene expression, growth factor overexpression or suppression, or loss of tumor suppressor genes, the question also must be raised whether these changes can influence PCNA expression levels and, if so, whether reliable "cell proliferation rates" can be determined in these lesions/tumors with any degree of certainty. In addition, the designation PCNA/cyclin (i.e., cyclin due to the presumably cell cycle-dependent synthesis and marked presence during S-phase of PCNA) has caused confusion with the unrelated cyclins that have been described in frogs, clams, sea urchins, yeast, and mammalian cells. Thus, it is the intention of this paper to review the current literature on PCNA and to distinguish PCNA from other cell cycleassociated proteins with regard to its biochemical and molecular characteristics as well as to its function in the cell cycle. Moreover, the advantages and pitfalls of current methodologies using PCNA as a cell proliferation marker in toxicology or as a prognostic tool in surgical pathology are discussed.

\section{DISCOVERY OF PCNA IN HUMANS AND ITS PRESENCE IN OTHER EUKARYOTES}

PCNA was first described by Miyachi et al. ${ }^{1}$ as a nuclear antigen, restricted to proliferating cells, that reacts with sera from some patients with the autoimmune disorder systemic lupus erythematosus (SLE), hence the name proliferating cell nuclear antigen. Tested via indirect immunofluorescence, these sera reacted with proliferating cells in a variety of tissues of the mouse, rabbit, and human, as well as with the dividing cell populations of baby hamster kidney, mouse fibroblast, SP 2/0 mouse hybridoma, Wil-2 human B diploid lymphocyte, Hep-2 human hepatoma, MCF-7 human breast carcinoma, Raji, MOLT-4 T lymphocyte, and Ehrlich ascite tumor cells lines. ${ }^{2}$ The presence of PCNA in various tissues and animal species, as previously mentioned, not only led to speculation as to the importance of this antigen, but also raised the question of its presence in other eukaryotes and possibly prokaryotes. Indeed, the development of monoclonal antibodies to $\mathrm{PCNA}^{3}$ and rat and human PCNA cDNA probes ${ }^{4-6}$ led to the discovery of PCNA-like proteins and homologous genes not only in eukaryotes, e.g., amphibians, mammals, marsupials, fish, birds, insects, ciliated protozoa, plants, and yeast, ${ }^{7-13}$ but also in viruses. ${ }^{14}$ Furthermore, amino acid sequence comparisons between human and rat PCNA revealed an extremely high degree of homology, ${ }^{4-6}$ with only 4 amino acid substitutions in 261 amino acids. Moreover, it was shown that the yeast type of PCNA was able to functionally interact with mammalian DNA polymerase. ${ }^{13}$ The presence of a similar PCNA gene throughout eukaryotes and, in some cases, viruses implies that a primordial gene for PCNA evolved more than one billion years ago at a period prior to the divergence into Planta and Animalia. ${ }^{15}$ The latter observations also indicate that PCNA is, phylogenetically, a structurally and functionally highly conserved protein and thus, based on the concept introduced by Kimura and Ohta ${ }^{16}$ on the principles governing molecular evolution, PCNA must play an essential role in the cell cycle and in the maintenance of species. However, prior to discussing the function(s) of PCNA in the cell cycle, it is of utmost importance to define this protein biochemically and molecularly in order to clearly distinguish it from other cell cycle-associated proteins, i.e., the cyclins.

\section{CHARACTERIZATION OF PCNA}

\section{A. Biochemical Characteristics}

The gene for PCNA has been highly conserved throughout the course of evolution, as is quite impressively demonstrated by the fact that rat PCNA cDNA probes have been successfully used for the detection of homologous PCNA gene sequences in Xenopus laevis, Drosophila melanogaster, two subspecies of rice, soybean, and tobacco. ${ }^{7,10,12}$ However, despite this high conservation, some differences are found in the DNA sequence and length of the gene coding for PCNA in the various species and genera. It is interesting to note that while in all genera there appears to be only one gene that codes for PCNA, disre- 
garding the surprising number of pseudogenes reported in mammalia whose function is not yet clear, the structure of the PCNA gene (DNA sequence and length and number of exons and introns) had undergone some modifications in the course of evolution among the genera, but has remained highly conserved within the respective genera, e.g., mammalia (Table 1). ${ }^{17}$ This may imply that with increasing complexity of the higher organisms, an enhanced need for the control of cell division and differentiation and thus for the regulation of PCNA expression developed. Indeed, in higher eukaryotes such as $D$. melanogaster, rice (Oryza sativa), and mice, the 5 -flanking regions of the respective PCNA genes appear to contain homeodomain protein-binding sites in addition to the promoter region. ${ }^{10,17,18}$ Homeodomain proteins have been shown to have a regulatory function in gene expression and to regulate via the modulation of important master genes, thus playing an important role in cell di- vision and differentiation. ${ }^{19,20}$ Furthermore, the presence of a similar number and nucleotide length of exons and introns in the PCNA gene of higher eukaryotes, namely, in the human and mouse PCNA gene, ${ }^{17,21}$ as well as the observation that intron 4 of the human PCNA gene codes for that part in the PCNA protein necessary for the correct regulation of PCNA levels in quiescent cells, ${ }^{22}$ further corroborate the assumption that enhanced possibilities of regulating gene expression had to be developed concurrently with the increasing complexity of higher eukaryotes.

The PCNA gene product is a nuclear nonhistone protein, as demonstrated by Takasaki et al. ${ }^{23}$ It was shown by Almendral and co-workers ${ }^{4}$ to have a domain (amino acids 66-80) resembling the $\alpha$-helix-turn- $\alpha$-helix putative DNAbinding domain of several other DNA-binding proteins. ${ }^{24}$ Generally, the PCNA found in the various species are all acidic proteins; however, more acidic and more basic variants can be dis-

TABLE 1

Comparison of PCNA Genes and PCNA Gene Products in Various Species and Genera

\begin{tabular}{|c|c|c|c|c|c|c|}
\hline \multirow[b]{2}{*}{ Species } & \multicolumn{2}{|c|}{ Gene } & \multicolumn{3}{|c|}{ Protein } & \multirow[b]{2}{*}{ Ref. } \\
\hline & $\begin{array}{c}\text { Exons/introns } \\
\text { per gene }\end{array}$ & $\begin{array}{l}\text { Pseudo- } \\
\text { genes }\end{array}$ & $\begin{array}{l}\text { Amino acids } \\
\text { No. }\end{array}$ & $\begin{array}{l}\text { Mol. } \\
\text { wt. } \\
\text { (Da) }\end{array}$ & $\begin{array}{l}\text { Homology } \\
(\%)\end{array}$ & \\
\hline Human & $6 / 5$ & 2 & 261 & $2926^{b}$ & 100 & $\begin{array}{l}4,22 \\
171,172\end{array}$ \\
\hline Rat & n.d. & 2 or 3 & 261 & $28748^{b}$ & 99.0 & 5,6 \\
\hline Mouse & $6 / 5$ & 2 & 261 & n.d. & 98.5 & 17 \\
\hline Rabbit & n.d. & n.d. & n.d. & $36000^{\circ}$ & n.d. & 47 \\
\hline $\begin{array}{l}\text { Frog } \\
\text { (Xenopus laevis) }\end{array}$ & n.d. & n.d. & n.d. & $36000^{c}$ & n.d. & 7,8 \\
\hline $\begin{array}{l}\text { Fly } \\
\text { (Drosophila melanogaster) }\end{array}$ & $2 / 1$ & n.d. & 260 & $28830^{b}$ & 70.4 & 10 \\
\hline $\begin{array}{l}\text { Yeast } \\
\text { (Saccharomyces cerevisiae) }\end{array}$ & n.d. & 0 & 258 & $28916^{b}$ & 35.0 & 13,34 \\
\hline $\begin{array}{l}\text { Rice } \\
\text { (Oryza sativa) }\end{array}$ & n.d. & n.d. & 263 & $29275^{b}$ & 61.0 & 12,173 \\
\hline $\begin{array}{l}\text { Periwinkle } \\
\text { (Cantharanthus roseus) }\end{array}$ & n.d. & n.d. & 268 & $29765^{b}$ & 85.0 & 174 \\
\hline $\begin{array}{l}\text { Baculovirus } \\
\text { (Autographa californica) }\end{array}$ & n.d. & n.d. & 165 & n.d. & 42.0 & 14 \\
\hline
\end{tabular}

Note: n.d. $=$ not determined.

a Amino acid sequence homology with human PCNA.

b Mol. wt. calculated from the deduced amino acid sequence of the PCNA coding sequence.

c Mol. wt. estimated via SDS-PAGE. 
tinguished. Currently two "variants" are well characterized: (1) an acidic variant found in humans, rat, hamster, and potoroo, with an isoelectric point (IP) of 4.5 to $4.8,25-27$ and (2) the more basic variant found in the mouse. ${ }^{27}$ Accordingly, these species-specific variants have different molecular weights (Table 1). It is important to note that when the molecular weights are calculated according to the respective amino acid sequence, the resultant weights (Table 1) are always lower than the 33,000 to 37,000 Da estimated by SDS-PAGE and immunoblotting. ${ }^{23,25,28,29}$ Sadaie and Mathews ${ }^{30}$ showed that the molecular weight of PCNA synthesized in an in vitro cell-free translation system is the same as that of PCNA isolated from cells, indicating that PCNA does not undergo extensive posttranslational modification. Thus post-translational modification cannot account for the difference in calculated and experimentally determined molecular weights. A possible explanation for this discrepancy is that PCNA migrates abnormally slowly in SDS-PAGE and the molecular weights have been overestimated. This phenomenon also has been observed with several other proteins, such as adenovirus E1A and c-myc protein. ${ }^{31,32}$

The functional unit of PCNA in mammalian cells, however, does not appear to be a proteinmonomer but rather a homodimer. ${ }^{25,33}$ In yeast, a tri- or tetramer is found. ${ }^{13}$ The molecular weights of the functional units of PCNA were calculated from the glycerol gradient sedimentation coefficient of $5.0 \mathrm{~s}$ and the respective Stokes radii (36.5 $\AA$ for mammalian PCNA and $40 \AA$ for the yeast analog) resulting in molecular weights of 75,000 Da for the mammalian PCNA homodimer $^{25}$ and approximately $82,000 \mathrm{Da}$ for the trior tetrameric yeast PCNA-analog. ${ }^{13}$ Thus, the functional units of the latter PCNAs are comparable in molecular weight and size. In addition, the observation that calf thymus PCNA can stimulate yeast polymerase III, the mammalian polymerase $\delta$ analog of the yeast Saccharomyces cerevisiae, or conversely that the yeast PCNA analog can stimulate the DNA-synthesizing abilities of calf thymus polymerase $\delta,{ }^{13}$ emphasizes the apparent high conservation of PCNA in its structure and function throughout the course of evolution. This function is conserved despite the fact that the amino acid sequence of the PCNAs found in mammals and yeast show very little homology. However, a sequence comparison between human, yeast, and baculovirus PCNA revealed that there are a few highly homologous domains, which might be important for proteinprotein interaction with the $\delta$ polymerases. ${ }^{34}$

\section{B. Expression of PCNA during the Cell Cycle}

In order to determine at what time point during the cell cycle PCNA synthesis is initiated, the PCNA content of synchronized cells, e.g., mouse 3T3 or human MOLT 4, was analyzed via immunofluorescence and flow cytometry, using monoclonal and/or polyclonal antibodies to PCNA. ${ }^{9,27,30,35-41}$ All investigators unanimously reported a maximum of staining intensity in the S-phase of cycling cells as well as the presence of PCNA at sites of ongoing DNA replication, as shown by the colocalization of PCNA and tritiated thymidine in the nucleus of replicating cells. ${ }^{9}$ Further investigation showed that the concentration of PCNA increased starting in late $G_{1}$ phase, reaching its maximum during S-phase, which is approximately sevenfold the concentration found in quiescent cells, ${ }^{9,30,35,38-41}$ and then to gradually decrease throughout $\mathrm{G}_{2}$ phase and mitosis. Using a full-length cDNA clone for the human PCNA, these observations have further been corroborated by Almendral and co-workers ${ }^{4}$ and Jaskulski and colleagues, ${ }^{42}$ who demonstrated that the expression of PCNA mRNA was low to undetectable in quiescent cells, whereas increased expression was detected 8 to $10 \mathrm{~h}$ after serum stimulation of quiescent $3 \mathrm{~T} 3$ cells, reaching a maximum induction of tenfold at 18 to 20 $\mathrm{h}$, which also is the peak of DNA synthesis in these cells. In addition, quiescent cells stimulated with fetal calf serum in the presence of 5-hydroxyurea, thus being inhibited from DNA synthesis, exhibited the same increase in PCNA mRNA as control cells without hydroxyurea. These experiments suggested that the induction of PCNA mRNA expression is independent of DNA synthesis. ${ }^{40,43}$ Despite the good rapport between PCNA detection via immunofluorescence and PCNA synthesis evidenced via mRNA lev- 
els, the findings by Bravo and MacDonaldBravo $^{36}$ evoked some doubt as to the reliability of PCNA detection via immunofluorescence. Indeed, when cells were fixed using organic solvents such as methanol, PCNA was detected at the intranuclear sites where DNA synthesis was taking place as shown by simultaneous $\left[{ }^{3} \mathrm{H}\right]$ thymidine (Tdr) incorporation. ${ }^{35,37}$ With this fixation technique, PCNA had a very granular distribution and was absent from the nucleoli in the early S-phase, whereas more prominent nucleolar staining was observed in the later stages of S-phase. On the other hand, when cells were fixed with aldehydes, the distribution of PCNA appeared different in that intense diffuse nuclear staining was observed throughout the cell cycle. ${ }^{36}$ This discrepancy was explained with the hypothesis that there are two forms of PCNA: an organic solvent insoluble form associated with the site of ongoing DNA synthesis, and a soluble form presumably not involved in DNA replication. ${ }^{36}$ This hypothesis was substantiated further by Kurki and co-workers, ${ }^{43}$ who found higher numbers of formaldehyde-fixed cells staining positive for PCNA than for bromodeoxyuridine (BrdU). Furthermore, Morris and Mathews ${ }^{44}$ demonstrated, in contrast to earlier studies, that the total concentration of PCNA varied at most two- to threefold during the cell cycle, but that a greater fraction of PCNA is insoluble due to chromatin association during S-phase than in other phases of the cell cycle, and, in corroboration with earlier findings by Bravo and MacDonald-Bravo, ${ }^{36}$ that a maximum of $30 \%$ of the PCNA present during $S$-phase was tightly associated with the nucleus and thus presumably present in replication complexes. Moreover, Morris and Mathews ${ }^{44}$ concluded that the cyclic synthesis of PCNA in proliferating HeLa cells maintained PCNA in excess of the amount necessary for DNA replication. If this were the case, the assessment of proliferating cells using the commercially available antibodies to PCNA ${ }^{1,3,7,8,41,45-48}$ would grossly overestimate the number of proliferating cells, as the antibodies a priori would not be able to distinguish between chromatin-associated and nonchromatinassociated PCNA. Indeed, Richter and coworkers $^{49}$ and Galand and Degraef ${ }^{50}$ found an excellent agreement between cell proliferation measurements obtained via PCNA and Tdr or
$\mathrm{BrdU}$ in tissues fixed with ethanol or methanol, whereas in tissues fixed with formalin or formaldehyde more PCNA than Tdr positive cells always were detected.$^{50}$ Coltrera and Gown, ${ }^{51}$ on the other hand, found no agreement or any correlation between the number of BrdU and PCNA positive alcohol-fixed cells in a variety of cell lines. However, prior to discussing the advantages and disadvantages of the various antibodies and the feasibility of using PCNA for cell proliferation studies, it is important to understand the regulation of PCNA mRNA expression and the function(s) of PCNA within the cell cycle.

As mentioned earlier, the levels of PCNA mRNA appear to be cycling during the cell cycle of 3 T3 cells. ${ }^{4,42}$ In these cells, the PCNA mRNA was shown to be inducible only by platelet-derived growth factor (PDGF), not by platelet-poor plasma. The expression of PCNA mRNA is inhibited by low concentrations of cycloheximide. ${ }^{42}$ In addition, PCNA mRNA was not expressed in serum-stimualted ts 13 cells at the restrictive temperature, ${ }^{42,52}$ ts 13 cells being G1specific, temperature-sensitive mutants of the cell cycle originally derived from baby hamster kidney cells and made quiescent by serum deprivation. ${ }^{42}$ The latter two findings suggest that the PCNA gene is growth factor regulated and, unlike early growth-regulated genes, PCNA requires the previous expression of other growthregulated genes (Figure 1). In contrast to other growth factor-regulated genes coding for proteins inherent to DNA synthesis, such as thymidine kinase, increased expression of PCNA mRNA can be induced by epidermal growth factor (EGF) or PDGF in the absence of other growth factors. ${ }^{42,52}$ Of the two most important pathways of regulating PCNA mRNA expression levels (Figure 1), the transcriptional regulation of PCNA mRNA steady-state levels involving the promoter region and intron 4 of the PCNA gene ${ }^{22,53}$ appears to play a minor role, whereas post-transcriptional regulation seems to predominate, as demonstrated in the latter experiments wherein the increase in mRNA levels that occurred in serumstimulated cells was largely post-transcriptionally regulated (Figure 1). ${ }^{52,53}$ To make it even more complex, the regulation of PCNA mRNA levels is different in continuously proliferating cells, wherein both the mRNA and the protein amounts 


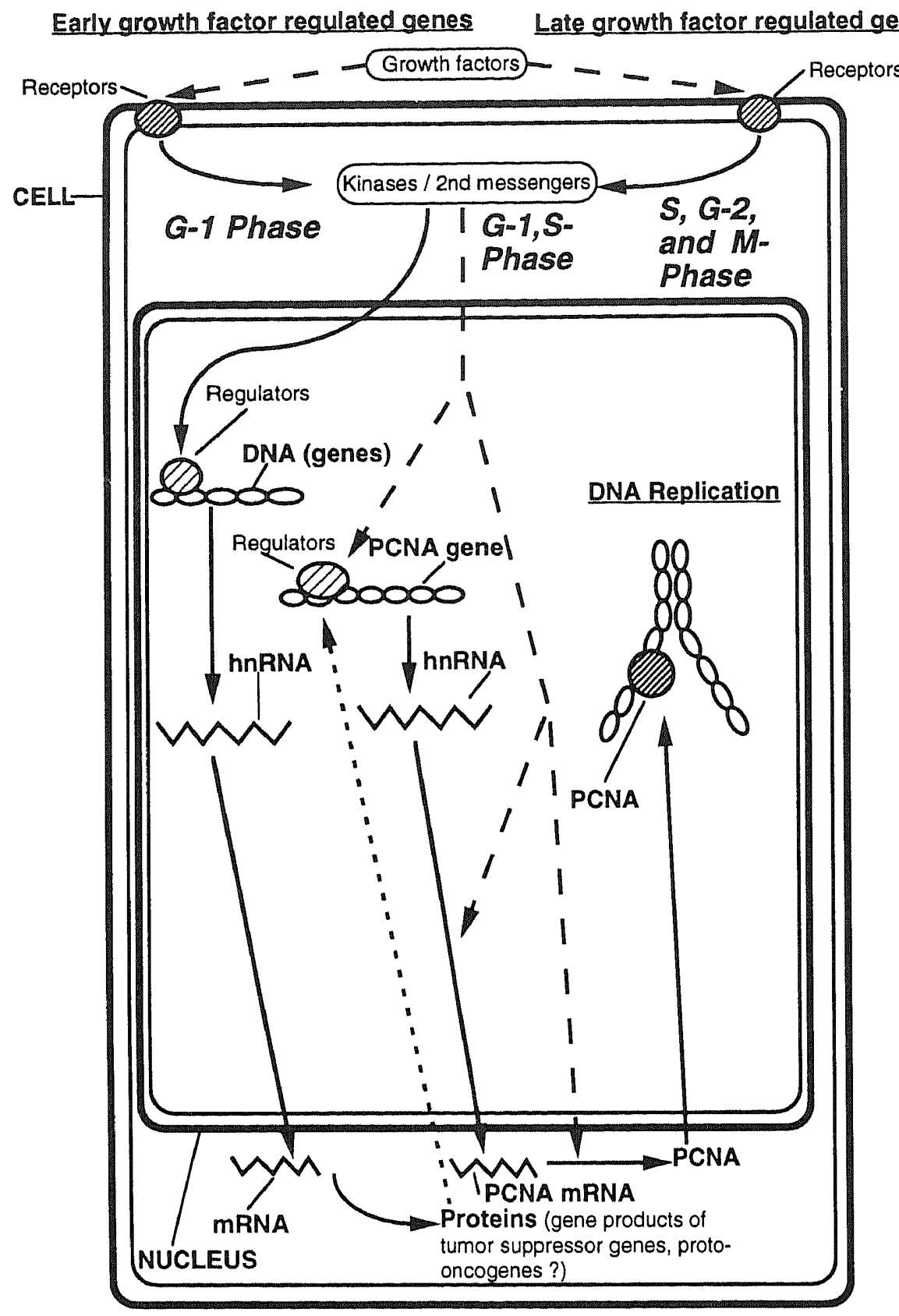

FIGURE 1. Schematic diagram of PCNA regulation during the cell cycle. Full arrows indicate the various steps in PCNA expression starting with gene transcription and ending with PCNA protein synthesis and the interaction of this protein during DNA synthesis. Dotted lines with arrows depict how and at which steps PCNA expression can be regulated.

vary little during the cell cycle. ${ }^{44,45,54}$ Furthermore, an overexpression of PCNA mRNA was found in the R3230AC mammary tumor of the rat, which was accompanied by an altered PCNA gene structure, ${ }^{54}$ emphasizing again that caution must be exercised when PCNA is used as a cell proliferation marker.

\section{FUNCTION OF PCNA IN THE CELL CYCLE}

\section{A. Cell Replication}

Based on the distribtuion pattern of PCNA during the cell cycle, the biochemical and struc- 
tural characteristics (putative DNA-binding domain) of the protein suggest that PCNA is intricately involved in DNA replication and possibly in cell cycle progression. Indeed, antibodies directed against PCNA reduced plasmid and chromosomal DNA replication in microinjected frog eggs, ${ }^{8}$ and inhibited the stimulation of DNA synthesis in MOLT-4 cells. ${ }^{55}$ Furthermore, after exposuring exponentially growing $\mathrm{Balb} / \mathrm{c} 3 \mathrm{~T} 3$ cells to antisense oligodeoxynucleotides to PCNA, DNA synthesis and mitosis were both completely suppressed. ${ }^{56}$ In addition, Tan and co-workers ${ }^{25}$ noticed that physically PCNA closely resembles a protein that regulates the activity of calf thymus DNA polymerase $\delta$. Further investigation revealed that PCNA and the auxiliary protein of calf thymus DNA polymerase $\delta$ were one and the same. ${ }^{33,57}$ PCNA also was shown to be required for replication of an SV40 DNA template in vitro in extracts from human 293 cells $^{33.58}$ as well as for cell replication of HeLa cells. ${ }^{59}$ In its interaction with calf thymus DNA polymerase $\delta$, PCNA increases the processivity of polymerase $\delta$ decisively. ${ }^{25}$ Within the concept of a two-polymerase hypothesis of eukaryotic replication, polymerase $\alpha$, with its tighly associated primase activity and semiprocessive mode of action, is ideally suited for the synthesis of the lagging strand. ${ }^{60}$ Conversely, polymerase $\delta$, lacking primase activity but possessing strand displacement activity and being highly processive in conjunction with the presence of PCNA, ${ }^{25,33}$ is capable of synthesizing long stretches of DNA as would be required of a leading strand polymerase (Figure 2). ${ }^{60-6.3}$ This hypothesis was tested using the SV40 replication system and the tests showed that in the absence of PCNA the leading strand synthesis was virtually abolished ${ }^{64-66}$ and that polymerase $\alpha$ was responsible for both the initiation and the synthesis of the lagging strand. Furthermore, leading strand synthesis was not inhibited when the SV40 replication system was treated with antibodies to polymerase $\alpha .{ }^{67}$ However, despite these clear indications that PCNA is directly involved in DNA synthesis and despite the fact that PCNA possesses a DNA-binding domain, no DNA-binding activities of PCNA could be detected. ${ }^{25}$ Therefore, the role of PCNA in DNA synthesis appears to be the increased binding of polymerase $\delta$ to poly (dA)/oligo(dT) in conjunction with the RF-A protein complex, RF-C pro- tein complex, and activator 1 protein complex, ${ }^{65-68}$ resulting in the stabilization of the polymerase-template/primer complex (Figure 2).

\section{B. DNA Excision Repair}

Besides the interaction of PCNA with polymerase $\delta$, PCNA can be detected in nuclei of non-S-phase cells following UV irradiation, suggesting an involvement of PCNA in the excision repair process. ${ }^{39,69}$ Inhibition of protein and DNA synthesis via cycloheximide and aphidicolin treatment, respectively, revealed that upon UV irradiation no new PCNA was synthesized, the PCNA observed via immunofluorescence was redistributed from an already existing pool within the nucleus, and this immunofluorescence staining was independent of DNA synthesis, thus suggesting that the relocation of PCNA was not triggered by DNA repair synthesis by itself but possibly preceded it. ${ }^{69}$ Furthermore, Toschi and Bravo $^{69}$ were able to show that the PCNA involved in excision repair was actually loosely attached to nuclear components and was in effect the part of the PCNA population that could not be detected in organic solvent fixed cells. In keeping with the hypothesis that the involvement of PCNA in the excision repair process precedes the actual DNA synthesis step, Shivji and coworkers ${ }^{70}$ and Coverley and co-workers ${ }^{71}$ investigated the excision repair process via fractionation of cell extracts and UV-irradiated plasmid DNA, which allowed them to resolve the excision repair process into discrete incision and polymerization stages. They were able to show that PCNA is required for the DNA synthesis that converts the nicked intermediates to complete repair events; however, this was only in conjunction with other proteins, e.g., xeroderma pigmentosum protein complement $\mathrm{A}$ (XP-A), human single-strand binding protein (HSSB), replication factor C (RF-C), and DNA polymerases $\delta$ or $\epsilon$ (Figure 3). However, with respect to excision repair, it must be stated that no direct interaction between PCNA and polymerase $\delta$ has so far been demonstrated. On the contrary, Syvaoja and Linn $^{72}$ and Nishida and co-workers ${ }^{73}$ described a PCNA-independent form of polymerase $\delta$, which appeared to be involved in the DNA repair process in UV-exposed Brij-58 cells. 


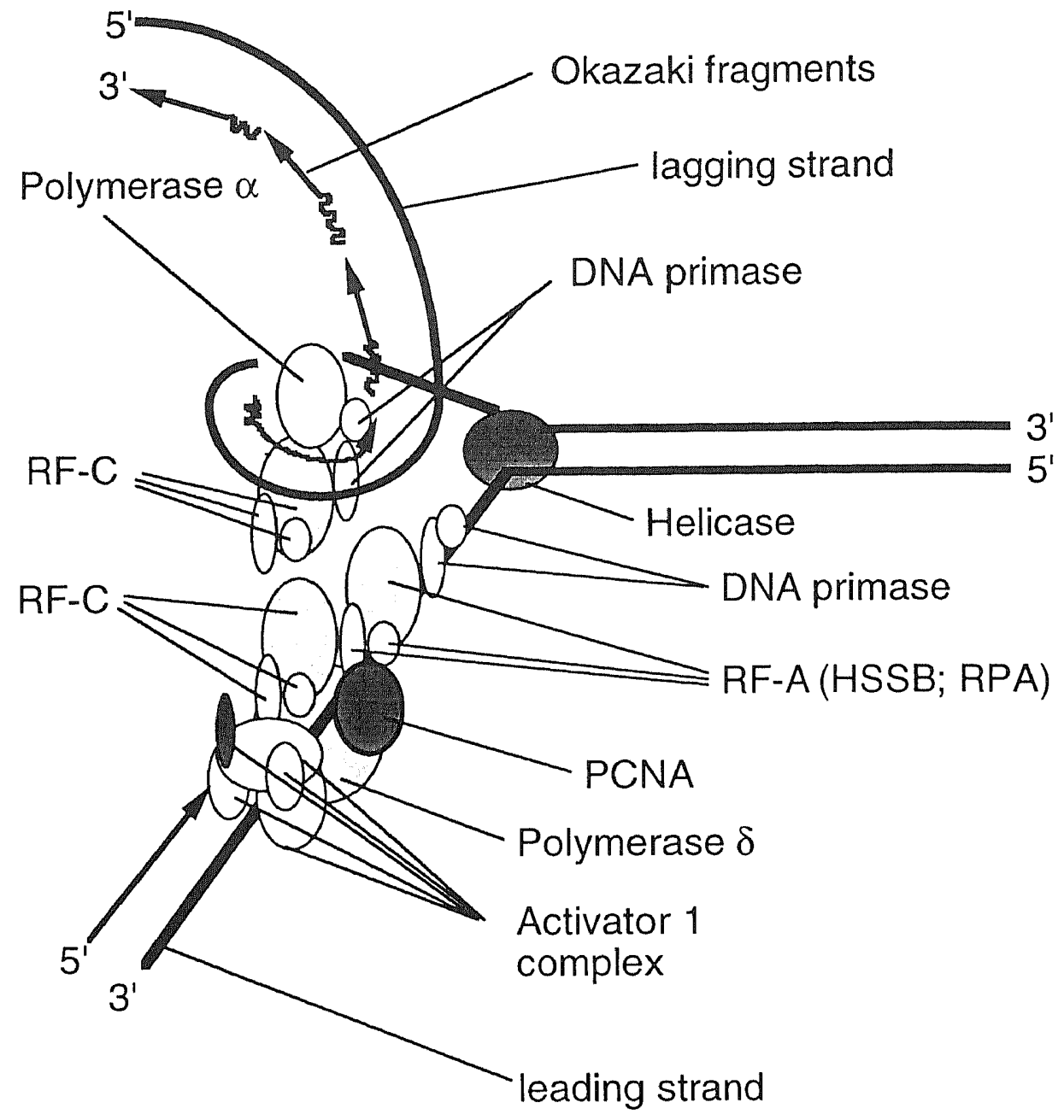

FIGURE 2. Schematic representation of the roles of PCNA and DNA polymerases $\alpha$ and $\delta$, replication factor $A$ (RF-A), also known as human single-strand binding protein (HSSB) or replication protein A (RPA), ${ }^{68,71,175}$ replication factor C (RF-C), ${ }^{65,66}$ DNA primase, and activator 1 complex ${ }^{68}$ in eukaryotic DNA replication. (Modified from Stillman, B., BioEssays, $9,56,1988$.)

The involvement of PCNA in DNA repair following UV irradiation and thus the detection of prior immunohistochemically undetectable PCNA forms must be taken into special consideration when using PCNA as a cell proliferation marker in epidermal tumors such as melanomas. In these tumors, immunohistochemical methods may well detect PCNA involved in DNA synthesis; however, not all PCNA positive cells need to represent dividing cells, meaning that a fair number of cells may be undergoing DNA repair. This applies not only to melanomas, as was shown to be the case, for example, in patients with acute myelogenous leukemia in which high levels of
PCNA correlated with DNA repair synthesis and was associated with enhanced resistance to chemotherapy but did not correlate with increased cell proliferation. ${ }^{74}$

\section{Interaction with Tumor Suppressor Genes and Oncogenes}

From the previous paragraphs, it should be clear that PCNA is involved in two mechanisms inherent to the cell cycle, i.e., DNA replication during the S-phase and DNA excision repair during the G2 phase and in quiescent cells. How- 
(i)

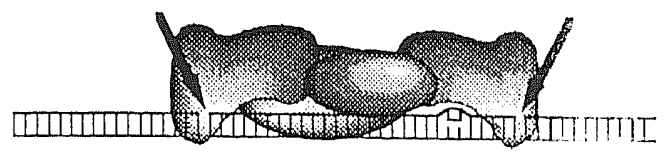

$\downarrow$

(ii)

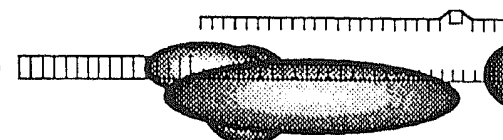

$\downarrow$

HSSB/RPA

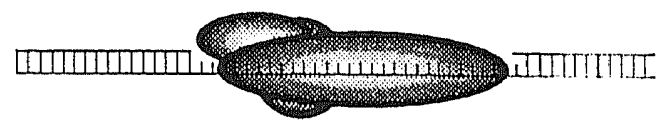

(DNA (iv)

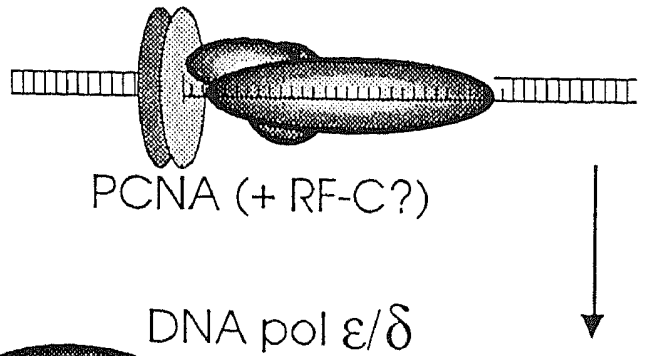

$(\mathrm{V})$

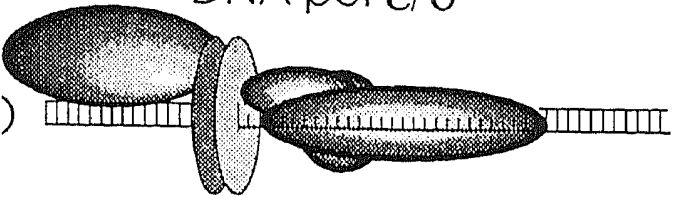

helicose)

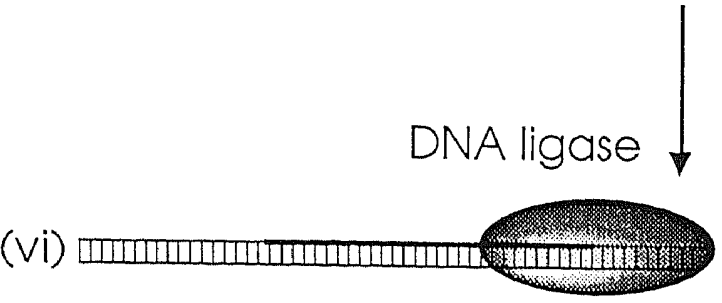

FIGURE 3. Model for nucleotide excision repair in mammalian cells. The model makes use of the data reported by Coverley et al. ${ }^{71}$ and Shivji et al. ${ }^{70}$ (i) Incisions are introduced about 20 nucleotides apart from the damage site ${ }^{176}$ by an unknown number of proteins, one of which is most probably the xeroderma pigmentosum $A$ polypeptide. ${ }^{168}$ (ii) The oligonucleotide containing DNA damage and the incision proteins are displaced, possibly by the human single-strand binding protein (HSSB) in concert with a DNA helicase. (iii) Degradation of the DNA gapped region may be prevented by HSSB. (iv) PCNA (in conjunction with RF-C?) binds to an incision site on the $5^{\prime}$ side of the gap, possibly mediated by protein-protein interactions with HSSB. (v) Repair synthesis is carried out by DNA polymerases $\epsilon$ or $\delta$. (vi) The repaired area is completed and sealed by a DNA ligase. (From Coverley, D., Kenny, M. K., Lane, D. P., and Wood, R. D., Nucleic Acids Res., 20(15), 3873, 1992. With permission.)

ever, in order to understand PCNA and its involvement in cell proliferation, it is necessary to understand not only how the expression of the PCNA gene and the level of the PCNA gene product are regulated, but also how PCNA gene expression and PCNA gene product levels may be affected by mutations, translocations, and allel loss in genes of cell proliferation and PCNA regulators.

Regarding altered PCNA RNA expression due to genetic events, constantly high expression levels of PCNA mRNA and gene product have been found in continuously proliferating cells, ${ }^{44,54}$ indicating that the gene(s) downregulating PCNA expression has either been missing, nonfunctional due to alterations in the gene(s), or suppressed in its function by other proliferation reg- ulators. Among the genes possibly regulating PCNA expression are the p53 and the retinoblastoma [p105(Rb)] gene products. Both of these gene products have been shown to have tumor suppressing capabilities in that they can inhibit transformation of cells to tumorigenic phenotypes. ${ }^{75-79}$ Furthermore, it was shown that the two tumor suppressor gene products in their underphosphorylated state keep cells from progressing from the G1 phase into S-phase, and thus play an important role in the control of the cell cycle (Figures 4 and 5). Phosphorylation of these gene products by the $\mathrm{cdc} 2(\mathrm{p} 34)$-cyclinC complex lifts the G1-S-phase barrier, allowing transition of the cell into S-phase. ${ }^{80-85}$

In view of the fact that PCNA is a late growth factor-regulated gene, its expression starting at 


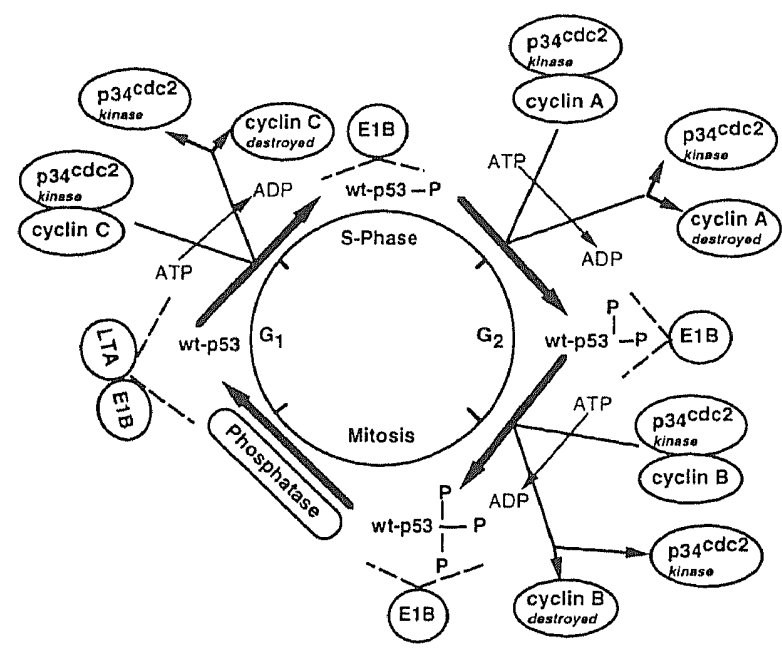

FIGURE 4. Schematic model of the cyclic phosphorylation and dephosphorylation of the human wild-type p53 protein by the p34(cdc2)-cyclin complexes and phosphatases during the cell cycle. Although the p34cyclin complex is depicted as the phosphokinase involved in the phosphorylation of p53 in every cell cycle phase, this has been explicitely shown to be the case for the p34-cyclin B complex in only the G2- to M-phase transition. ${ }^{84}$ However, p34-cyclin complexes have been implicated as the phosphokinase complexes involved in the G1- to S-phase, S- to G2-phase, and G2- to Mphase transitions in the human cell cycle. ${ }^{85}$ The $p 53$ protein is depicted here with three phosphate groups in the M-phase; however, the actual degree of p53 phosphorylation during the cell cycle has not been determined yet, with the exception that p53 is underphosphorylated in the G1 phase, phosphorylated upon entry into S-phase, and additionally phosphorylated during the transition from the $\mathrm{G} 2$ - to the $M$-phase..$^{78,84}$ In addition, the putative interaction possibilities of the DNA tumor virus gene products large $T$ antigen (LTA) and adenovirus $\mathrm{E} 1 \mathrm{~B}(\mathrm{E} 1 \mathrm{~B})$ with the various p53 phosphorylation states are shown. ${ }^{94,177}$ However, there is no evidence at this time that E1B can bind to phosphorylated $\mathrm{p} 53$. The association of E1B with phosphorylated p53 is merely hypothetical, and was drawn in analogy to the known association of the E1A protein with phosphoryalted $\mathrm{p} 105(\mathrm{Rb})$ depicted in Figure $5 .^{82,178}$

the end of the G1 phase (Figure 1), the question arises whether $\mathrm{p} 53$ and/or $\mathrm{p} 105(\mathrm{Rb})$ have a regulatory effect on PCNA expression. Indeed, both p53 and p105(Rb) have domains with DNA-binding abilities. ${ }^{86-89}$ However, thus far there is evidence only for the p53 gene product demonstrating that the wild-type $\mathrm{p} 53$ protein selectively downregulates PCNA mRNA and protein expression (Figure 6) in conjunction with the inhibition

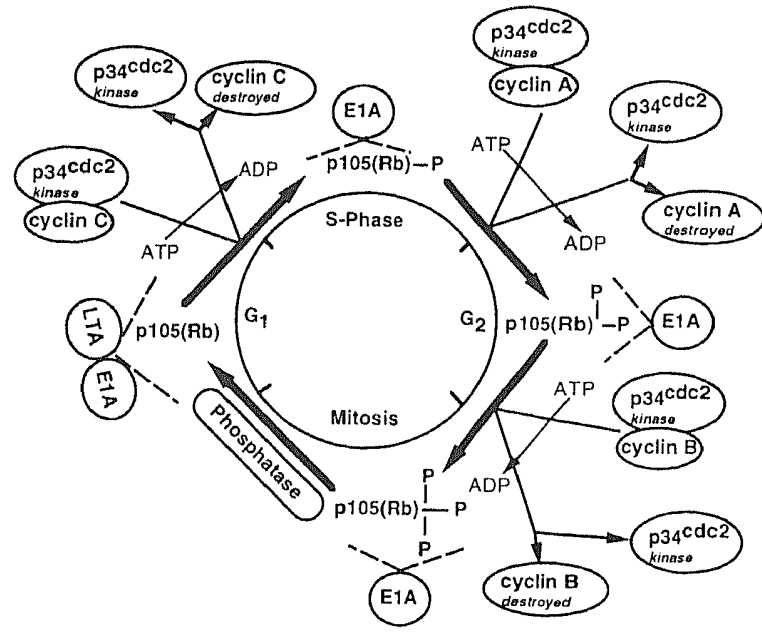

FIGURE 5. Schematic model of the cyclic phosphorylation ${ }^{80}$ and dephosphorylation of the human p105(Rb) protein by the p34(cdc2)-cyclin complexes and phosphatases during the cell cycle. Although the p34-cyclin complex is depicted as the phosphokinase involved in the phosphorylation of p105(Rb) in every cell cycle phase, it has not been explicitely shown that cyclins are part of this phosphokinase complex implicated in p105(Rb) phosphorylation. However, the p34(cdc2) kinase has been implicated as the phosphokinase involved in p105(Rb) phosphorylation, ${ }^{179}$ and the p34-cyclin complexes have been shown to be important in the G- to S-phase, S- to G2-phase, and G2to M-phase transitions of the human cell cycle. ${ }^{85}$ The model also depicts the interaction possibilities of the DNA tumor virus gene products large $T$ antigen (LTA) and adenovirus $E 1 A(E 1 A)$ with the various $p 105(R b)$ phosphorylation states. ${ }^{82,178}$

of cell cycle progression. ${ }^{90}$ Alteration of $\mathrm{p} 53$ by mutation, as often observed in human tumors, leads to gene products that are unable to bind to DNA, ${ }^{86}$ thus raising the question whether mutated p53 can still regulate PCNA expression. Alteration or inactivation of $\mathrm{p} 53$ by mutation, or by its interaction with oncogene products of DNA tumor viruses, can lead to abrogated cell cycle control and subsequently to cancer. ${ }^{77,91}$ Although direct evidence is lacking, experiments with SV40 DNA virus-transformed keratinocytes show that PCNA expression is increased in these transformed cells, irrespective of the cell cycle stage, thus suggesting that the PCNA expression control by regulatory proteins is abrogated. ${ }^{37}$ Furthermore, the conformational changes observed in the gene products of mutated $\mathrm{p} 53^{92}$ also could 
toxicological studies. Over/underestimation of cell proliferation could occur under circumstances in which PCNA protein is over/underexpressed as the result of functional changes in genes regulating PCNA expression. Indeed, overexpression of PCNA was found to correlate with overexpression of wild-type and mutated p53 in human colorectal tumors. ${ }^{102}$ Thus, more research studying tumor suppressor gene and oncogene expression in conjunction with PCNA (over/under)expression is clearly needed.

\section{DIFFERENCES OF CYCLIN(S) VS. PCNA}

Numerous publications describe a protein involved in the cell cycle as PCNA/cyclin; however, just this designation can be quite misleading inasmuch as PCNA and cyclin(s) are not one and the same, although both PCNA and cyclin(s) appear to be characterized by a cyclic expression during the cell cycle, have been highly conserved throughout evolution in many organisms, and seem to be intricately involved in cell replication. Indeed, cyclins describe a class of proteins that are found in viruses, ${ }^{103}$ clams, ${ }^{104}$ frogs, ${ }^{105}$ sea urchins, ${ }^{106,107}$ yeast, ${ }^{108.109}$ flies,${ }^{85,103}$ and humans, ${ }^{85,103}$ are highly conserved, ${ }^{103}$ and have a approximate molecular weight of $56 \mathrm{kDa} .{ }^{110} \mathrm{On}$ the basis of sequence comparisons, cyclins have been divided into two classes (A and B) and most organisms contain both types, ${ }^{10,111}$ However, most recent findings suggest further classes of cyclins, i.e., the $\mathrm{C}, \mathrm{D}$, and $\mathrm{E}$ classes in humans as well as the Cig 1 and Mcs 2 classes in yeast, ${ }^{85,112}$ Of importance is that cyclins are synthesized during interphase, associate into a complex with the p34 ${ }^{\mathrm{cdc} 2}$ kinase (Figure 4 and 5), and are destroyed by cyclin-degrading enzymes after the cell enters S-phase (cyclins A, C, D, E), G2 phase (cyclins A), or mitosis (cyclins A and B). ${ }^{11,113}$ Cyclin A was shown to play a major role in the control of DNA replication in that the microinjection of mammalian cells with plasmids encoding antisense cyclin A cDNA or with affinity-purified anti-cyclin $\mathrm{A}$ antibodies during the $\mathrm{Gl}$ phase led to inhibition of DNA synthesis. ${ }^{114}$ Although it was demonstrated that the cyclin A-p33 ${ }^{\text {cak2 } 2}$ kinase complex, i.e., the $\mathrm{p} 33^{\mathrm{edk} 2}$ kinase belonging to the p34 ${ }^{\text {cdc2 }}$ kinase family, has a sequence-specific
DNA-binding activity, ${ }^{115}$ this DNA-binding activity was associated with the phosphorylation of other DNA-bound substrates during S-phase (Figures 4 and 5) and was not, as is the case with PCNA, associated with the processes directly involved in DNA synthesis. Thus, cyclins are biochemically, structurally, and functionally different from PCNA and therefore the term PCNA/ cyclin is erroneous and should be avoided.

\section{CELL PROLIFERATION MEASUREMENTS USING PCNA ANTIBODIES}

There is increasing evidence that enhanced cell proliferation, whether induced by chemicals, UV or ionizing radiation, or genetic alterations in cell cycle-regulating genes, may be a significant factor in the etiology of tumor development. ${ }^{16-120}$ Furthermore, the assessment of the rate of cell proliferation in an organ or lesion has been shown to be enormously useful for understanding at least some of the aspects of the underlying mechanisms involved in the development and progression of induced and spontaneously occurring lesions and tumors. ${ }^{120-122}$ Thus, several methods for measuring cell proliferation, such as flow cytometry and immunohistochemistry, have evolved in the last few decades. Among these, methods using exogenously applied thymidine analogs (BrdU and ${ }^{3}[\mathrm{H}]$-thymidine [Tdr]) for marking the DNA synthesized during S-phase have seen widespread application and gained acceptance by the scientific community. However, the major disadvantages of these techniques is that postmortem (post-fixation) analysis of cell proliferation in organisms, organs, biopsies, or cell lines is not possible without prior in vivo application of these S-phase markers. Thus, with the discovery of PCNA, with its presumably cyclic synthesis, involvement in DNA replication, and marked presence in S-phase cells, and the development of commercially available PCNA antibodies, ${ }^{1,3,41,46,48,123,124}$ much attention has focused on PCNA as a new marker for proliferating cells. In contrast to techniques using BrdU or Tdr, flow cytometric and immunohistochemical analysis using the endogenously formed PCNA could potentially allow retrospective assessment of cell proliferation in archived 
material. ${ }^{125-127}$ However, in order to achieve reliable results with this new cell proliferation marker, it is not enough to understand the role and function of this endogenous protein in the cell, but rather a thorough knowledge of the possibilities, limitations, and uncertainties involved in the use of the techniques using this cell proliferation marker is a prerequisite.

\section{A. Antibodies}

As mentioned earlier, PCNA and the respective autoantibodies were discovered in patients presenting with SLE. These polyclonal autoantibodies were the first antibodies available for studying the role and function of PCNA. $1,7,8,27,38,41,55,123,124$ In the beginning, the use of these polyclonal autoantibodies were problematic as these antibodies also recognized proteins other than PCNA. ${ }^{7,47}$ The preparation of a monospecific immunoglobulin G-type anti-PCNA via absorption of serum from an SLE patient to immobilized rabbit kidney extract, apparently containing negligible amounts of PCNA but abundant amounts of other autoantigens, solved the problem of unspecific antigen reaction. ${ }^{3,7}$ In a further step, a number of monoclonal antibodies to PCNA were developed. ${ }^{3,46,48}$ Among these, three are commercially available: a murine $\operatorname{IgM}$ designated "19A2", a murine IgG designated " $19 \mathrm{~F} 4$ ", 3,46 and a genetically engineered murine IgG isotype designated "PC10". 48 Whereas the polyclonal PCNA autoantibodies were demonstrated to recognize at least two different epitopes at the $\mathrm{N}$ - and the C-terminals of the PCNA protein, the epitopes recognized by the 19A2 and 19F4 monoclonal antibodies appear to reside more to the center of the protein. ${ }^{46}$ The $\mathrm{PC} 10$ antibody was shown to have staining characteristics similar to those observed with the 19A2 and 19F4 antibodies when tested using immunofluorescence, ${ }^{48}$ suggesting that the epitope recognized by $\mathrm{PC} 10$ also may reside in the center of the protein. Epitope location and recognition by antibodies are important factors to be considered whenever PCNA is used as a cell proliferation marker. Indeed, Waseem and $\mathrm{Lane}^{48}$ found that among their 11 genetically engineered PCNA antibodies one antibody (PC9) appeared to recognize a completely discrete epitope, meaning that when monkey kidney $\mathrm{CV}-1$ cells were stained with PC9 only the nucleoli were positive for PCNA, thus suggesting that this specific epitope, not recognized by other PCNA antibodies, is present only on the nucleolar form and is absent or masked on the nucleoplasmic form of PCNA. This may indicate that the PCNA protein possibly undergoes conformational changes, depending on its location within the nucleus and its function during the cell cycle. On the other hand, these differences may reflect methodological discrepancies such as different fixation procedures, etc. The former hypothesis is corroborated by the observation that in studies in which the presence of PCNA was measured in proliferating MOLT-4 cells via flow cytometry or immunofluorescence, polyclonal antibodies reacted with PCNA in cells from late $\mathrm{G} 1$ to $\mathrm{G} 2 / \mathrm{M}$ phase of the cell cycle, ${ }^{40,123}$ whereas the monoclonal antibodies 19A2 and 19F4 behaved more like S-phase markers. ${ }^{41}$ The latter hypothesis is contrasted by the observation that the monoclonal antibodies 19A2 and PC10 used for immunohistological detection of PCNA in formalin-fixed paraffin-embedded tissues were found to stain S-phase cells as well as cells undergoing mitosis. ${ }^{45,128}$ Thus, with regard to the use of PCNA antibodies in cell proliferation measurement techniques, the question must be asked if indeed PCNA undergoes conformational changes, and whether some of the epitopes may be masked during specific phases of the cell cycle and thus are not readily detectable by PCNA antibodies; or whether epitope masking is induced by the type of fixative used and the duration of fixation and thus represents a methodological artifact. Clearly, more studies, such as were commenced by Waseem and Lane, ${ }^{48}$ are needed that are aimed at understanding changes in epitope accessibility during the cell cycle. A possible future tool for such studies may be the use of a number of PCNA antibodies recognizing different well-characterized epitopes.

\section{B. Methodologies}

\section{Immunocytochemistry and Immunohistochemistry}

\section{a. Freshly Fixed Cells and Tissues}

Standard techniques of immunofluorescent staining or biotin-streptavidin-chromagen com- 
plexation in conjunction with the appropriate microscopy have been used for the detection of PCNA and subsequently for measurement of cell proliferation. ${ }^{3,45,48,50,128-131}$ These techniques are applicable not only to recently frozen or paraffinembedded sections or to cytospins from cultured cells, ${ }^{9,35,38-41,43}$ but also possibly to archival tissues. ${ }^{126,127,132-136}$ However, as already mentioned in Section III.B, all of these methods have a serious flaw in that the quality of the PCNA stain, i.e., the number of cells and type of cell cycle phases positive for PCNA (Figure 7), may vary depending on the methods used for tissue/cell preservation. Indeed, Garcia and co-workers ${ }^{130}$ were not able to achieve acceptable staining in tissues fixed with formalin and embedded in paraffin, whereas tissues fixed with alcohol or methacarn proved to be no problem. Fixation-related differences in PCNA staining also were reported for immunofluorescence stainings (see Section III.B), ${ }^{35,36,43,137}$ where indeed it was postulated that different PCNA "forms" could be identified pending the use of either alcohols or aldehydes as fixatives. These findings were corroborated by Galand and Degraef, ${ }^{50}$ who found that tissue staining with the 19A2 antibody following methanol fixation would allow the detection only of $S$-phase cells, whereas in tissues fixed with aldehydes, the 19A2 antibody detected PCNA in cells of all phases of cell replication, with the exception of quiescent cells. On the other hand, Rowlands and co-workers, ${ }^{138}$ using the PC10 antibody, found no differences in the degree of staining between sections fixed with absolute ethanol, methanol, Carnoy's fluid, $10 \%$ formol-saline, or $10 \%$ neutral buffered formalin; however, they were unable to achieve adequate staining in Bouin's fixed sections. This stands in contrast to

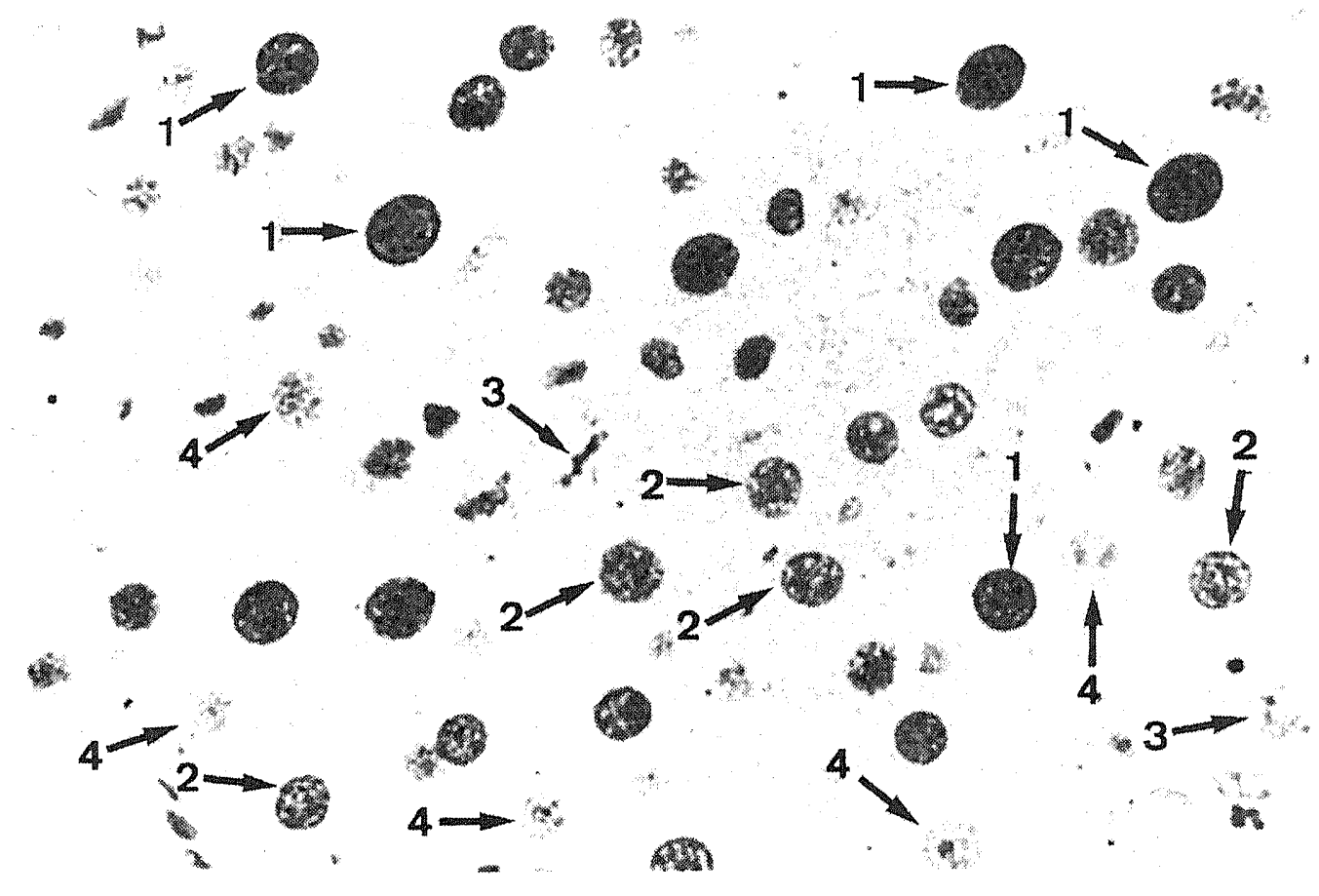

FIGURE 7. Liver section of a male F344 rat $24 \mathrm{~h}$ after partial hepatectomy stained with PCNA (19A2 antibody, biotin-streptavidin, AEC chromagen). This liver tissue was fixed with $10 \%$ formalin for a maximum of 7 years and stored in paraffin for up to 18 months. Various phases of the cell cycle are positive for PCNA, i.e., dark staining $(1 \rightarrow)$ nuclei depicting S-phase cells, light staining nuclei $(2 \rightarrow)$ representing G1-S and G2 cells, and cells with cytoplasmic staining usually depicting mitoses $(3 \rightarrow)$, whereas nonstaining nuclei $(4 \rightarrow)$ represent quiescent $(G 0)$ cells. (Magnification $\times$ 100.) (From Dietrich, D. R., Candrian, R., Marsman, D. S., Popp, J. A., Kaufmann, W. K., and Swenberg, J. A., in preparation.) 
the findings by Hall and co-workers ${ }^{45}$ and Dietrich and Curtis, ${ }^{133}$ who achieved accpetable staining with the PC10 antibody in sections of Bouins' fixed human and rainbow trout tissues (Figure 8). To further confuse the matter, Hall and co-workers ${ }^{45}$ found no PCNA immunoreactivity in normal liver sections assayed with the PC10 antibody, whereas Foley et al., 125,128,139 Nakamura and co-workers, ${ }^{140,141}$ and Dietrich and co-workers ${ }^{126,132}$ found PCNA positive staining in liver sections of normal and treated young and adult rats (Figures 7, 9, and 10), mice, ${ }^{125}$ and rainbow trout ${ }^{133}$ (Figure 8) using the 19A2 and the PC10 antibody, respectively. Unfortunately, not only the choice of antibody and type of fixative used but also the duration of tissue fixation can influence the quality of the PCNA stain. Indeed, it was reported that staining in rat small intestine and human colon is greatly reduced after $48 \mathrm{~h}$ of fixation and is virtually abolished after $72 \mathrm{~h},{ }^{45}$ a trait that most likely can be explained by progressive protein-aldehyde crosslinking with increasing fixation time ${ }^{142}$ and thus with protein conformational changes that consequently mask the PCNA epitopes. Therefore the study protocol plays a critical role with regard to PCNA immunohistochemical staining, and many of the discrepancies discussed previously may be related to study protocol differences as well as to the choice of PCNA antibody and staining procedure.

\section{b. Archival Tissues}

In view of the problems involved in the immunohistochemical detection of PCNA in recently fixed tissues, the question must be asked whether it is at all possible to do any retrospective cell proliferation studies in tissues that were fixed a long time ago and in which the tissue fixation protocol usually is unknown or in tissues that

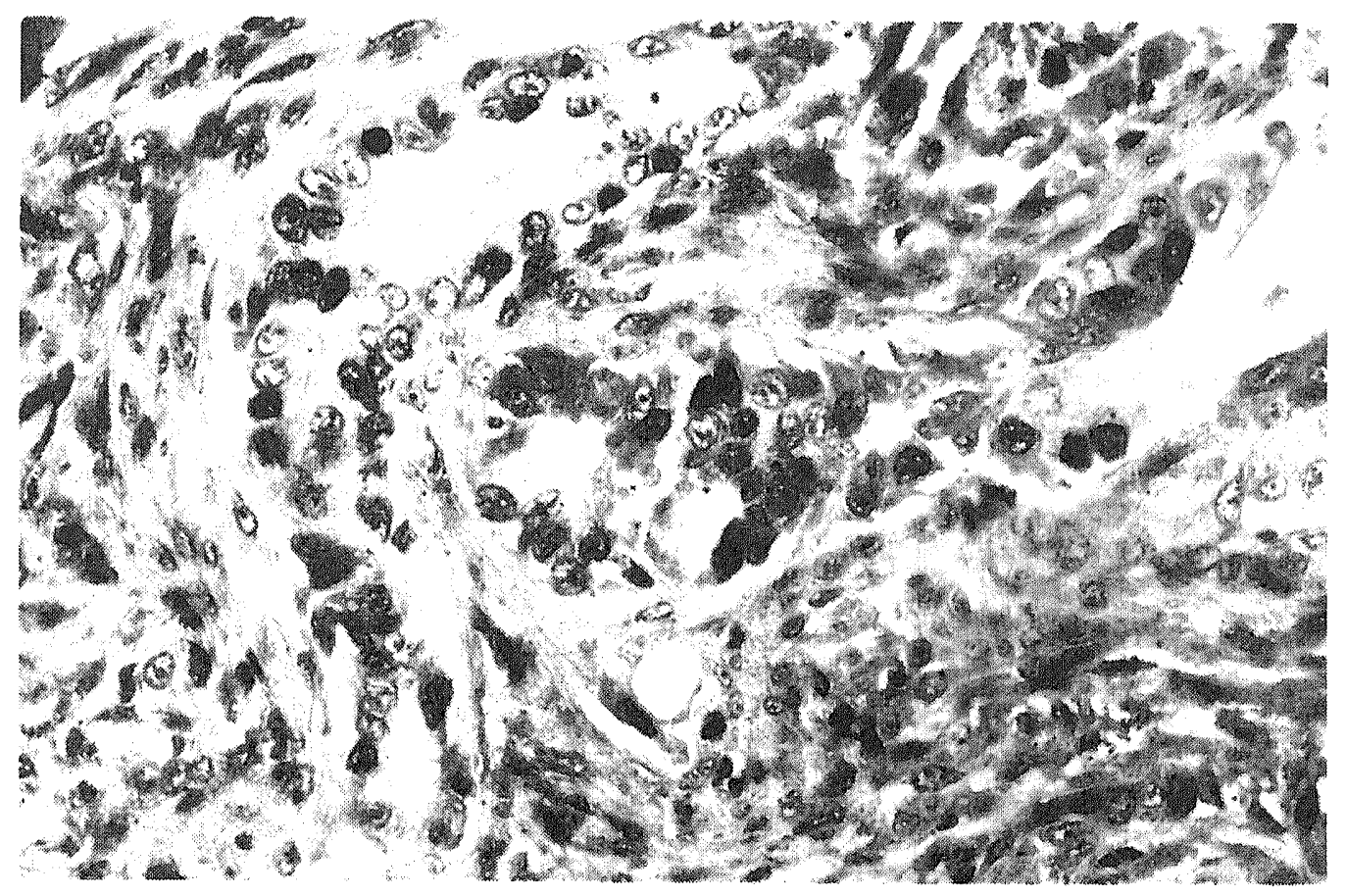

FIGURE 8. Liver tumor of a rainbow trout treated with aflatoxin $B_{t}$. This section was fixed with Bouin's, embedded in paraffin, sectioned, and stained with PCNA (PC10 antibody, biotin-streptavidin, Fast-Red ${ }^{\text {Im }}$ chromogen) for assessment of cell proliferation. Dark staining nuclei depict S-phase cells; light staining nuclei represent G1-S and G2 cells; nonstaining nuclei represent quiescent $(\mathrm{GO})$ cells. (Magnification $\times$ 400.) (From Dietrich, D. R. and Curtis, L. R., unpublished results.) 


\section{BrdU and PCNA Labeling Index in Rat Renal Tubule Cells}

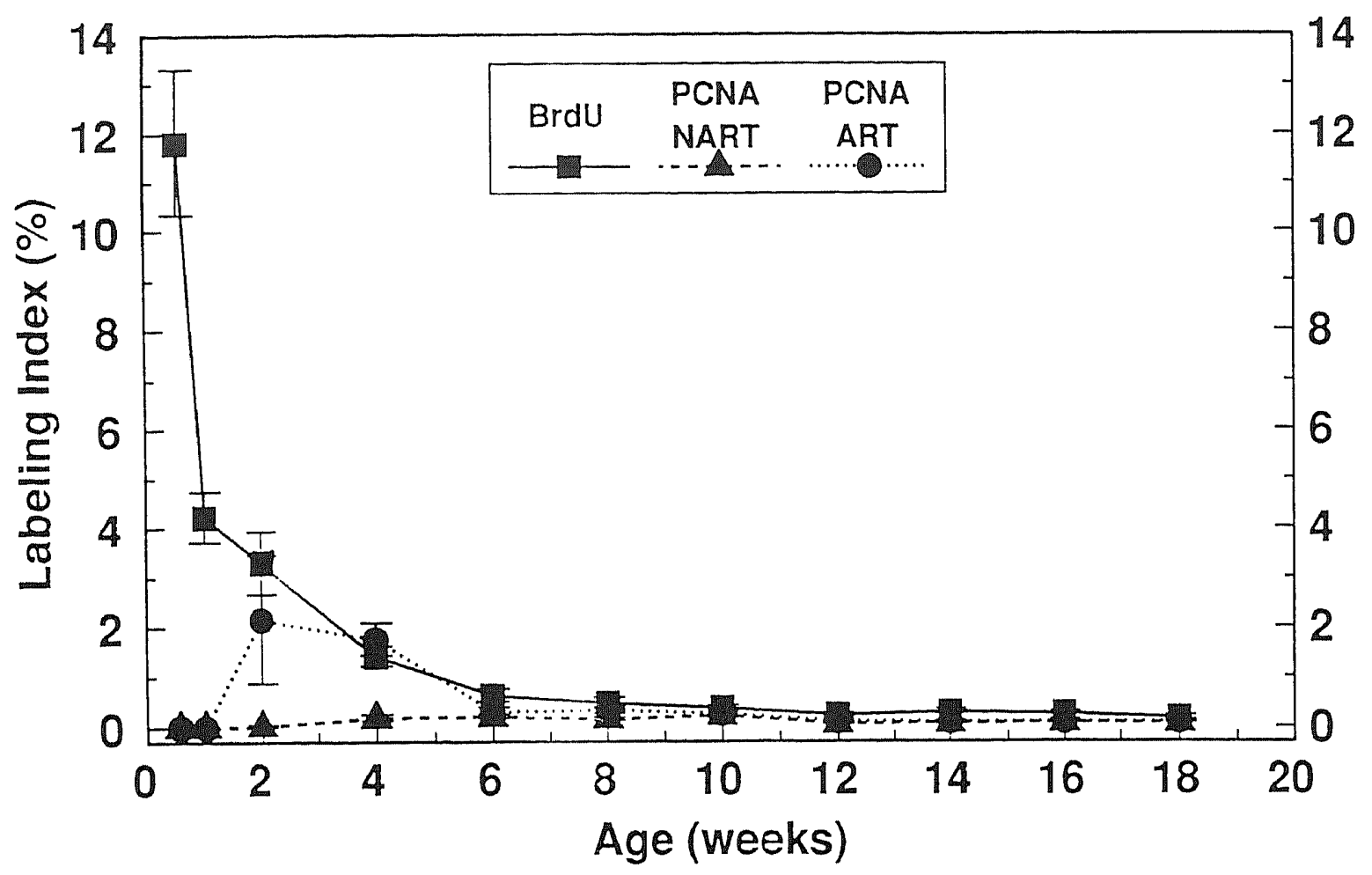

FIGURE 9. Comparison of BrdU and PCNA immunostaining for the assessment of cell proliferation in kidney sections of young male F344 rats at varying time points after birth, showing that PCNA and BrdU are comparable in older animals, whereas they vary decisively in very young animals. The LI were obtained by counting the number of labeled nuclei in 1000 renal tubule epithelial cells. BrdU, 5-bromo-2'-deoxyuridine labeled nuclei; PCNA-NART, PCNA immunostained S-phase nuclei obtained without the use of the antigen retrieval technique (ART); PCNAART, PCNA immunostained S-phase nuclei obtained via the use of ART. (From Nakamura, J., Dietrich, D. R., Schoonhaven, R., and Swenberg, J. A., in preparation.)

have been kept in fixatives for years. PCNA staining was achieved in conventionally fixed and histologically processed archival human tissues, usually encompassing a 4-h formalin fixation and paraffin embedding, using both the $\mathrm{PC} 10^{135,143}$ and 19A2 antibody ${ }^{130,133,16}$ (Figure 11) and a conventional staining procedure. ${ }^{45,128,134}$ For tissues that were fixed for longer than $48 \mathrm{~h}$, a special tissue treatment using the "Antigen Retrieval Solution $^{\mathrm{TM}}$ " (ARS) and microwaving was developed, ${ }^{126,127,132,140-142}$ making it possible to carry out PCNA immunostaining in tissues that had been preserved in formalin for up to 7 years (Figure 7). ${ }^{126}$ It is hypothesized that microwaving the tissues in conjunction with ARS results in breaking the protein-aldehyde crosslinks and in recon- stitution of the protein, thus unmasking the epitopes for PCNA immunohistochemistry (Figures $7,9$, and 10$).{ }^{142}$ Although different nuclear staining intensities possibly depicting the G0, G1-S, $S, G 2$, and $M$ phases of the cell cycle can be observed (Figure 7), and despite the fact that it is generally accepted that the most intensive staining nuclei depict cells in S-phase whereas nonstaining cells represent quiescent (G0) cells, ${ }^{126-128,132,139,144}$ the question needs to be answered whether or not the observed stained cells represent all cells in the process of replication. Keeping in mind that PCNA is present, although in low concentrations, in quiescent cells," the application of techniques such as microwaving for unmasking PCNA epitopes in archival tissues 


\section{BrdU and PCNA Labeling Index in Rat Hepatic Cells}

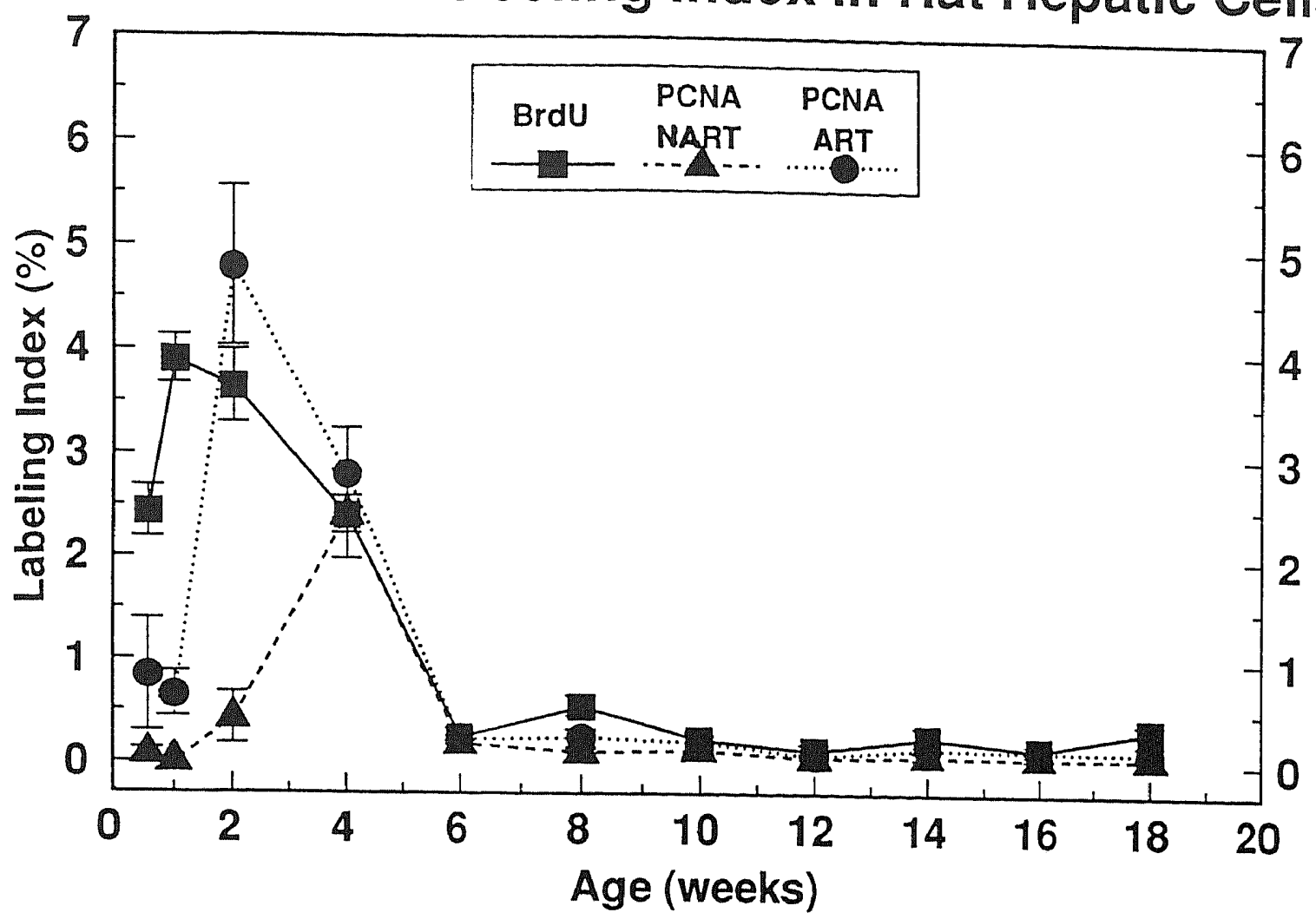

FIGURE 10. Comparison of BrdU and PCNA immunostaining for the assessment of cell proliferation in liver sections of young male F344 rats at varying time points after birth, showing that PCNA and BrdU are comparable in older animals, whereas they vary decisively in very young animals. The LI were obtained by counting the number of labeled nuclei in 1000 hepatocytes. BrdU, 5-bromo-2'-deoxyuridine labeled nuclei; PCNA-NART, PCNA immunostained S-phase nuclei obtained without the use of the antigen retrival technique (ART); PCNA-ART, PCNA immunostained S-phase nuclei obtained via the use of ART. (From Nakamura, J., Dietrich, D. R., Schoonhaven, R., and Swenberg, J. A., in preparation.)

also may unwantingly unravel PCNA epitopes usually masked in quiescent cells and thus could give the impression of a higher fraction of proliferating cells than is actually present (Figures 9 and 10; Table 2). On the other hand, PCNA immunohistochemical staining was shown to be highly variable from tissue to tissue and even within sections of the same tissue, ${ }^{45,126,132}$ mostly as a result of tissue handling (preservation, fixation, embedding) and section thickness, indicating that cell proliferation measurements using PCNA immunohistochemistry may underestimate the actual size of the proliferating cell population due to methodological artifacts (Figures 9 and 10 ). One possible solution to this problem may be the concurrent use of flow cytometric analyses and PCNA immunohistochemistry, thus measuring the actual proliferating cell population and distinguishing different phases of the cell cycle in addition to determining the ploidy of the cells studied (Figure 12), ${ }^{145}$ while having simultaneously stained sections depicting the morphological characteristics of the tissue. If PCNA immunohistochemistry is to be used as a tool for assessing cell proliferating, the results obtained with this technique also must be comparable to those obtained with established techniques such as Tdr autoradiography or BrdU immunohistochemistry. Therefore, it will be necessary to investigate whether the PCNA proliferation index (LI), defined as labeled cells/unlabeled + labeled cells, should incorporate all PCNA positive cells or only those that are considered to be in S-phase. 


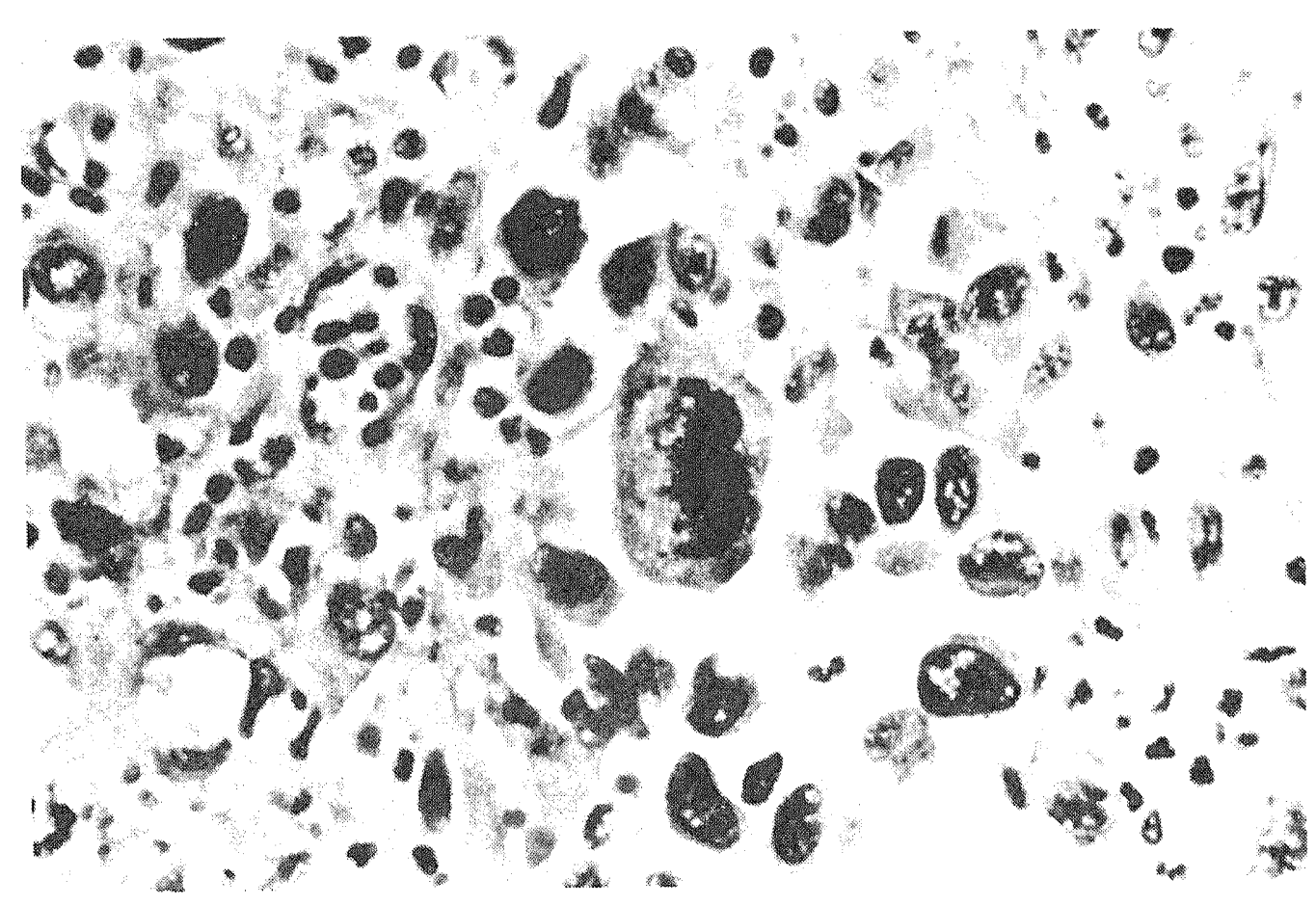

FIGURE 11. PCNA immunostained section of an archival human melanoma, biopsied, fixed with formalin, and embedded in paraffin in 1974 and sectioned and stained in 1992. Note the diversity of cellular morphology (nuclear size and form) and staining characteristics (light, granular, and dark stained nuclei). (Magnification $\times 400$.) (From Woosley, J. T. and Dietrich, D. R., J. Cutan. Pathol., 19, 557, 1992. With permission.)

\section{Flow Cytometry}

Flow cytometry is a method that enables the simultaneous quantitation of laser beam, xenon-, or mercury-arc-stimulated fluorescence of dyes and antibodies bound to cellular components in individual cells. This method has been successfully used for the distinction of cell cycle phases, i.e., by the determination of the amount of DNA present in the nucleus, ${ }^{146}$ an especially important factor that must be taken into consideration whenever cell proliferation is assessed in the liver where heptocytes, especially in rats and mice, are known to consist of several ploidy classes. ${ }^{145,147}$ The amount of DNA can be measured indirectly via the fluorescence intensity of propidium iodide, a fluorescent dye that binds to DNA in a stoichiometric manner. ${ }^{147,148}$ The use of fluorescein isothyocyanate (FITC)-conjugated secondary antibodies allowed quantitation of the presence of certain antigens, such as PCNA-antibodies and thus measurement of the PCNA content simultaneously with DNA content. ${ }^{40,41,43,45,137}$ The concentration of PCNA during the cell cycle and the spatial distribution within the nucleus were studied using various cell lines, e.g., mouse spleenocytes, mouse hybridoma, SP2/0, MOLT$4,{ }^{40,41}$ human $\mathrm{T}$ lymphocytes, ${ }^{4.3} \mathrm{HeLa},{ }^{4.5}$ and human breast carcinoma MCF-7. ${ }^{137}$ Similar to the problems of fixation encountered in immunohistochemistry and immunocytochemistry of tissue sections and cultured cells, respectively, alcohol fixation of cells resulted in the detection of PCNA primarily in S-phase cells and to a lesser extent in G2, M, or in G1-phase cells and was clearly confined to the nucleus, ${ }^{40,43}$ whereas paraformaldehyde fixation allowed not only the detection of PCNA in all phases of the cell cycle with the exception of quiescent cells, but also the PCNA present in the cytoplasm, ${ }^{41}$ especially during mitosis, ${ }^{137} \mathrm{a}$ trait also observed in histochemically stained tissue sections and immunocytochemically stained cytospins of cultured cells. ${ }^{126,128,137}$ The presence of PCNA in the cytoplasm of cells in G2 and M phase is assumed to be a direct consequence of the dissolution of 
TABLE 2

Labeling Induces (니) Obtained with PCNA Staining and Tdr

Autoradiography and Mitotic Indices (MI) in Liver Sections of Male F344

Rats at Varying Time Points after Partial Hepatectomy (PH)

$\begin{aligned} & \text { A: Liver Tissues Fixed in 10\% Formalin for a Maximum of } 7 \text { Days and Stored in Paraffin } \\ & \text { for up to } 18 \text { Months. When Comparing only S-Phase LI, the LI Obtained with PCNA Are } \\ & \text { Significantly Higher at the Early Time Points of the Experiment }\end{aligned}$
$\begin{aligned} & \text { Tdr [LI (\%)] } \\ & \text { S-phase }\end{aligned}$
Group

a Significantly different ( $p<0.05$, one-factor ANOVA) from the 24-h Tdr data.

b Significantly different ( $p<0.05$, one-factor ANOVA) from the 24-h PCNA data.

c Significantly different $(p<0.05$, one-factor ANOVA) from the corresponding Tdr data.

B: Liver Tissues Fixed in 10\% Formalin for a Maximum of 7 Years and Stored in Paraffin for up to 18 Months. When Comparing only S-Phase LI, the LI Obtained with PCNA Are Not Significantly Higher at Any Time Point of the Experiment

$\begin{array}{cccccccc}\text { Group } & \begin{array}{c}\text { Tdr [LI (\%)] } \\ \text { S-phase }\end{array} & \boldsymbol{n} & \text { S-phase } & \begin{array}{c}\text { PCNA [LI (\%)] } \\ \text { G1-S/G2 }\end{array} & \text { Go } & \boldsymbol{n} & \begin{array}{c}\text { MI (\%) } \\ \text { Mitosis }\end{array} \\ \text { Control } & 0.2 \pm 0.4 & 3 & 1.2 \pm 0.4 & 9 \pm 6 & 89 \pm 6 & 3 & 0.4 \pm 0.2 \\ \text { 4-h PH } & 1.3 \pm 0.2 & 3 & 1.8 \pm 0.9 & 6 \pm 2 & 91 \pm 3 & 3 & 0.5 \pm 0.5 \\ \text { 12-h PH } & 0.4 \pm 0.1 & 2^{\text {a }} & 2.4 \pm 0.9 & 17 \pm 6 & 81 \pm 7 & 3 & 0.4 \pm 0.2 \\ \text { 15-h PH } & 6 \pm 3 & 3 & 3 \pm 1 & 24 \pm 1 & 74 \pm 2 & 3 & 0.3 \pm 0.1 \\ \text { 18-h PH } & 8 \pm 15 & 4 & 5 \pm 2 & 28 \pm 17 & 67 \pm 19 & 3^{\text {c }} & 0.2 \pm 0.1 \\ \text { 21-h PH } & \text { No label } & 3^{\text {b }} & 7 \pm 7 & 28 \pm 9 & 65 \pm 15 & 2^{\text {c }} & 0.3 \pm 0.1 \\ \text { 24-h PH } & 13 \pm 2 & 3 & 13 \pm 5 & 32 \pm 14 & 49 \pm 4 & 2^{\text {c }} & 6.3 \pm 5.4\end{array}$

Note: $n$ depicts the number of liver sections available for cell proliferation measurements.

a No data were available for one animal.

b No Tdr labeling was achieved in the original study.

c Due to faint or inadequate PCNA staining, the data of one animal per group were not included.

From Dietrich, D. R., Candrian, R., Marsman, D. S., Popp, J. A., Kaufmann, W. K., and Swenberg, J. A., in preparation.

the nuclear envelope during G2 and the coalescence of nucleoplasmic and cytoplasmic matrix during mitosis. ${ }^{128}$ Generally, the highest PCNA content was found in S-phase cells, at least in nontransformed cell lines, whereas PCNA levels appeared to be high irrespective of the cell cycle phase in continuously proliferating HeLa cells. ${ }^{45}$ Thus, with regard to the cyclic variation of PCNA content, the agreement between the immunohistochemical, immunocytochemical, and flow cy- tometric analysis of proliferating cells, using PCNA antibodies, is generally good. The chief deficiency in the use of flow cytometry is the unavoidable loss of tissue architecture and the concomitant loss of information with respect to the anatomical distribution of cell proliferative activity. However, with the advent of techniques that allow flow cytometric analysis in tissues that had been conventionally fixed previously with formalin and embedded in paraffin, ${ }^{149-151}$ it is 


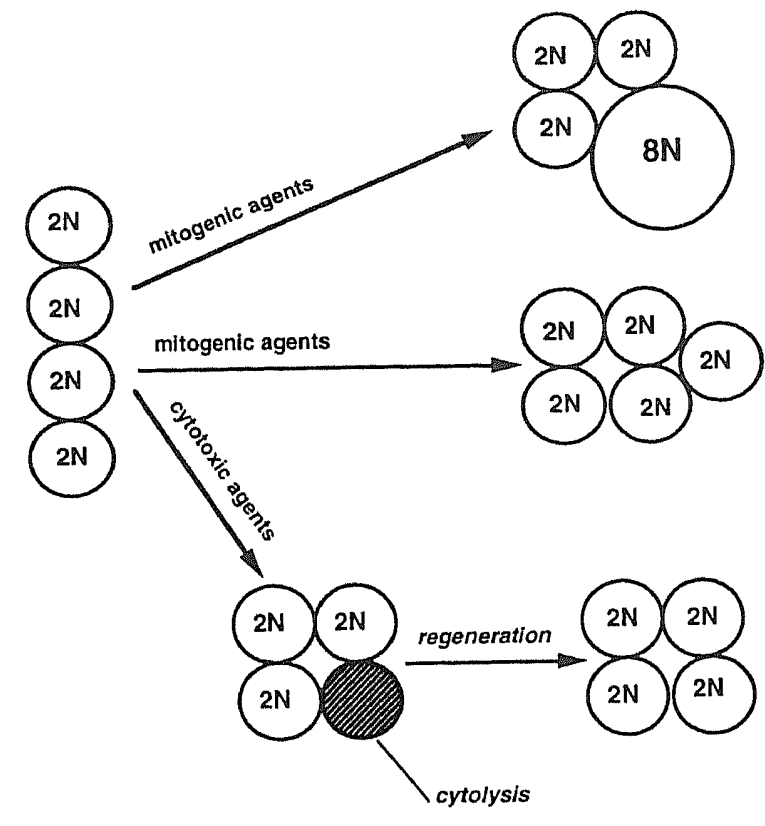

FIGURE 12. Schematic diagram showing three possible effects induced after xenobiotic insult that can lead to replicative DNA synthesis and that a priori are not distinguishable from one another solely by determining the LI via PCNA immunohistochemistry.

possible to compare directly the proliferative compartment of a lesion observed in a tissue section with the respective data on DNA content obtained via flow cytometry. Such studies have been carried out with regard to the prognostic value of the proliferative index assessed via PCNA immunostaining and flow cytometric measurement of DNA content in human gastrointestinal lymphomas, ${ }^{152}$ gastric carcinomas, ${ }^{153}$ and hemangiopericytomas. ${ }^{143}$ Interestingly, a good correlation between the immunohistochemically determined PCNA LI and the $\mathrm{S}+\mathrm{G} 2+\mathrm{M}$ phase fraction determined by flow cytometry was found in the gastrointestinal lymphomas, ${ }^{152}$ whereas no such correlation could be demonstrated for the gastric carcinomas ${ }^{153}$ or the hemangiopericytomas. ${ }^{143}$ Indeed, such comparisons are extremely valuable in cases where an increased expression of PCNA is observed. However, no correlation of this expression to cell replication can be demonstrated, as was shown to be the case in human acute myelogenous leukemias, ${ }^{74}$ thus indicating that the increased PCNA expression in this case is possibly not related to its function in cell replicative DNA synthesis but rather to DNA ex- cision repair. One disadvantage of retrospective flow cytometry yet to be resolved is that at present is is possible to measure only the DNA content, not the PCNA content, in the cells of the respective tissue. The reason for this may be the fact that a pepsin digestion step is needed in order to render the tumor into the single cell moiety necessary for flow cytometric analysis, yet pepsin digestion as well as any other form of enzyme digestion has been shown to virtually abolish PCNA immunoreactivity. ${ }^{45}$ In addition, to validate retrospective flow cytometric analysis in paraffin-embedded tissues with regard to cell proliferation assessments, it would be useful to compare the measured DNA contents to those of a simultaneously analyzed exogenously applied S-phase marker, such as BrdU. Although paraffin-embedded biopsy samples of humans that had been treated with BrdU prior to biopsy are most likely not easily accessible, numerous samples from toxicology and carcinogenesis studies in rodents, all with well-defined treatment protocols, are obtainable and therefore would allow the validation of cell proliferation measurements via retrospective flow cytometric analysis and its use in toxicology and pathology in conjunction with PCNA immunohistochemistry.

\section{Comparison of Cell Proliferation Measurement Using PCNA with Exogenous and Endogenous Cell Proliferation Markers Such As BrdU, $\mathrm{Tdr}$, and $\mathrm{Ki}-67$}

Evaluations of PCNA as a cell proliferation marker via a comparison with the well-known and established exogenously applied cell proliferation markers Tdr and BrdU were carried out using immunocytochemistry on cultured cells grown on glass coverslips and on cytospins of cultured cells such as human amnion, mouse NIH 3T3, HeLa, MCF-7 human breast cancer, human peripheral blood mononuclear, human A-431 malignant carcinoma, human SK-5 nontransformed fibroblast, and HUVE (nontransformed human umbilical vein endothelial) cells. ${ }^{36,38,45,51,137}$ Not surprisingly, in synchronized cell cultures, the proliferation measured with PCNA and Tdr or BrdU correlated ex- 
tremely well. $36,38,45$ However, comparative cell cycle analysis of PCNA and BrdU distribution in nonsynchronized MCF-7 cells indicated that replication patterns visualized by PCNA immunostaining were not a measure of replicative activity per se. ${ }^{137}$ Similar observations were made by Coltrera and Gown, ${ }^{51}$ who found that the BrdU positive subpopulation of the SK-5 cell line was not identical to or had any overlap with the PCNA positive subpopulation. Interestingly, a coimmunostain with another endogenous cell proliferation marker, Ki-67, gave similar results in SK5 cells as did PCNA immunostaining, whereas this was not the case for the three other cell lines studied (HeLa, A-431, HUVE). In two other cell lines (HeLa, A-431), the latter authors found that BrdU positive cells formed inclusive subsets of the PCNA positive population. This suggests that the PCNA expression levels may be different in cell lines with inherently different proliferation rates, and thus cannot uncritically be used as a marker for cell proliferation. This hypothesis was corroborated by Hall and co-workers, ${ }^{45}$ who demonstrated that the expression of PCNA remained constantly high and independent of the cell cycle phase in continuously proliferating HeLa cells.

Studies comparing cell proliferation measurements obtained via immunohistochemical staining of tissue sections with PCNA and BrdU, ' Tdr, or Ki-67 have evolved recently and include freshly fixed as well as archival tissues. ${ }^{49,50,126,132,139-141,144,154-159}$ In freshly fixed rat colon, liver and kidney, and human colon, the agreement between cell proliferation measurements obtained via BrdU and PCNA appears to be excellent (Figures 9 and 10), ${ }^{49,140,141,157}$ especially if only S-phase cells were counted. Slightly higher labeling indices were obtained with PCNA in rodent and human liver and gastrointestinal tract; ${ }^{156}$ however, this was shown to be the result of the counting procedure, i.e., all staining nuclei were counted, including non-Sphase cells. Similar results were reported by Galand and Degraef, ${ }^{50}$ who found the PCNA LI to markedly exceed the Tdr LI in formaldehydefixed tissue sections, whereas in methanol-fixed tissues, the PCNA LI agreed well with the Tdr LI. These differences are due mainly to the fact that in methanol-fixed sections primarily S-phase cells are PCNA positive, whereas in addition to the $S$-phase cells, non-S-phase cells stain positive in formaldehyde-fixed tissues (see Section VI.B). Thus, cell proliferation measurements in freshly fixed tissues via PCNA immunohistochemistry appear to agree quite well with those obtained using the two well-known exogenously applied S-phase markers, BrdU and Tdr, and this suggests that PCNA immunohistochemistry is a viable method for cell proliferation measurement in freshly fixed paraffin-embedded tissues. Yet most of these studies mentioned were carried out in human tissues or in tissues of adult rodents, with the exception of the experiments carried out by Nakamura and co-workers, ${ }^{140,141}$ in which agerelated cell proliferation in liver and kidney was studied using PCNA and BrdU immunohistochemistry. These experiments showed that in animals aged 6 weeks and older there are no differences in PCNA LI and BrdU LI (Figures 9 and 10). Surprisingly, the PCNA LI did not agree with those achieved with BrdU in the kidney and liver of male rats up to 6 and 4 weeks of age, respectively (Figures 9 and 10). Using the "An-

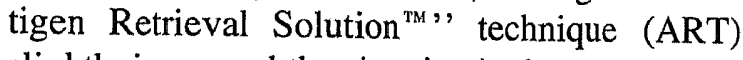
slightly improved the situation in that near agreement between PCNA LI and BrdU LI was achieved in rats as young as 2 weeks of age. However, these experiments indicate that PCNA may not be a suitable proliferation marker in very young animals. The reasons for this "underexpression" of PCNA in very young animals certainly merits further investigation.

Comparisons between cell proliferation measurements via PCNA and BrdU immunohistochemistry or $\mathrm{Tdr}$ autoradiography also have been carried out using archival tissues. 126,132,139,158,159 All of these studies used rat or mouse liver tissues archived from earlier toxicological studies, with well-known treatment protocols, and the ART technique for improved PCNA immunohistochemical staining. Among these tissues, some had been fixed very briefly, paraffin embedded, and then remained in paraffin blocks from 18 to 26 months (Table 2A), ${ }^{132,139,158,159}$ while others had been kept in the fixative for 7 years, paraffin embedded, and then remained in paraffin blocks for 18 months (Table 2B). ${ }^{126}$ Generally, excellent agreement was observed between S-phase PCNA $\mathrm{LI}$ and BrdU LI or Tdr LI irrespective of the 
duration of tissue fixation or paraffin storage, with the exception of one study in which the PCNA LI slightly exceeded the LI determined via $\mathrm{Tdr}$ autoradiography (Table $2 \mathrm{~A}$ ). This discrepancy may be explained by the low number of tissues analyzed and by the variability in staining intensities found to occur between and within treatment groups of the latter study, thus making a clear distinction of S-phase from non-S-phase cells sometimes difficult. ${ }^{126}$ It has to be emphasized that in order to carry out retrospective cell proliferation measurements via PCNA immunohistochemistry it must be possible to distinguish clearly the S-phase from non-S-phase cells. However, despite the paucity of retrospective studies comparing PCNA with other cell proliferation markers, the present data indicate that PCNA is a suitable marker for retrospecitve cell proliferation measurement in archival tissues.

PCNA immunohistochemistry also was correlated to Ki-67 immunohistochemistry in human malignant lymphomas, ${ }^{154}$ brain tumors, ${ }^{160}$ and tumor xenografts of the LoVo cell line. ${ }^{155}$ While good agreement between Ki-67 and PCNA was found in malignant lymphomas and low-grade gliomas, ${ }^{154,160}$ little correlation to $\mathrm{Ki}-67$ and growth fraction, estimated via fraction of labeled mitosis, ${ }^{155}$ was observed in astrocytomas, highgrade and mixed gliomas, Schwannomas, and xenograft tumors, ${ }^{155,160}$ indicating that PCNA immunohistochemistry cannot be uncritically used as a proliferation marker in tumors.

\section{PERSPECTIVES, FUTURE NEEDS, AND APPLICATION OF PCNA AS A PROLIFERATION MARKER IN TOXICOLOGY AND AS A PROGNOSTIC MARKER IN SURGICAL PATHOLOGY}

\section{A. Toxicology}

In its toxicological application, PCNA immunohistochemistry or, if even possibly, PCNA flow cytometry, should enable the measurement of cell proliferation in archival tissues thus preventing researchers from having to repeat completed studies currently lacking adequate proliferation data. So far, it has been established that PCNA may be used as a cell proliferation marker as it compares quite well with other well-known S-phase markers such as BrdU or Tdr, and may reflect chemically induced cell proliferation even better than BrdU or Tdr especially if the proliferative index $(\mathrm{PI})$, incorporating all PCNA positive cells, is used rather than the S-phase (LI) ${ }^{158,159}$ In addition, PCNA analysis has the potential to identify the specific cell populations (G1, S, G2, M) that exist in the cell cycle and, if feasible, may lead to quantitating the effects of a compound on the different cell populations and thus to potentially critical information in understanding compound-induced cell proliferation. ${ }^{119}$ Indeed, the presence of cytoplasmic PCNA during the late $G 2$ and $M$ phase of the cell cycle ${ }^{50,126,128}$ may provide further insight into the effects of chemicals on the distribution of PCNA within the cell during the cell cycle. However, for many tissues with a normally low proliferation rate, e.g., liver, kidney, pancreas, etc., the use of PCNA immunohistochemistry may prove to be problematic as only few cells will be positive for PCNA and of these very few will be in S-phase, meaning that the LIs generated with PCNA immunohistochemistry are more comparable to those generated by BrdU or Tdr administered as a pulse-dose rather than those from BrdU or Tdr administered continuously. ${ }^{139}$ Furthermore, in contrast to the exogenously applied proliferation markers BrdU or $\mathrm{Tdr}$, the expression of PCNA, being a cell cycle-regulated protein, may be influenced by the compound the animal was treated with, indicating that PCNA immunohistochemistry could under- or overestimate the actual proliferation rate. Indeed, the immunosuppressants dexamethasone and cyclosporin were shown to inhibit PCNA expression as well as T-lymphocyte proliferation, whereas the DNA synthesis inhibitors cytarabin and hydroxyurea prevented lymphocyte proliferation but not PCNA expression. ${ }^{43}$ Furthermore, Foley and coworkers ${ }^{139}$ reported similar LI of PCNA and Tdr up to $24 \mathrm{~h}$ after 4-acetylaminofluorene (4-AAF) treatment; however, $48 \mathrm{~h}$ after 4-AAF treatment, the PCNA LI remained increased while the Tdr LI returned to control values. These discrepancies could have stemmed from a potential induction of growth factors by the nongenotoxic 4AAF resulting in the overexpression of PCNA (Figure 1). Overexpression of PCNA also was 
reported in conjunction with poligeenan-induced colonic cell proliferation in F344 rats. ${ }^{161}$ In this study, poligeenan, a nongenotoxic sulfated polysaccharide known to induce colorectal tumors, was fed in the diet for 64 days after which the animals were returned to the NIH-07 diet alone for 28 days. Despite removal of poligeenan from the diet, the PCNA levels in the upper third of the crypt remained 11-fold above control levels for 28 days, indicating either a decreased ability of the colon crypt cells to adapt rates of cell proliferation or a deregulated expression or catabolism of PCNA resulting from poligeenan treatment. Deregulation of the cyclic expression of PCNA was demonstrated earlier by Hall and co-workers, ${ }^{45}$ who found PCNA remained at high levels, irrespective of the cell cycle phase, in continuously proliferating HeLa cells. On the other hand, Ahnen and co-workers ${ }^{162}$ found similar cell proliferation-associated staining patterns for PCNA and Tdr in normal colon and colonic tumors of rats treated with the known colon carcinogen dimethlhydrazine, suggesting that in their study PCNA expression was a reliable marker of the proliferative compartment in the rat colon. Interestingly, the cell proliferative response was confined to the lower third of the crypt in the rectum, whereas in the proximal and mid-colon, staining extended into the mid to upper third of the crypt.

Regenerative cell proliferation determined with PCNA immunohistochemistry in mouse lung epithelia following acute injury with butylated hydroxytoluene ${ }^{131}$ showed that the increased expression of PCNA correlated well with increased Tdr incorporation, indicating that PCNA expression is not altered during enhanced regenerative proliferation. Similarly, the effects of the mitogenic hepatocarcinogenic agents $\mathrm{Wy}-14,643$ and 1,4-dichlorobenzene on liver cell proliferation were measured using PCNA and BrdU immunohistochemistry as well as Trd autoradiography ${ }^{158,159}$ and demonstrated that mitogeninduced cell proliferation can be reliably determined with PCNA immunohistochemistry and that the two hepatocarcinogenic agents do not induce overexpression of PCNA.

However, in view of the paucity of data regarding compound-induced enhanced cell proliferation measured via PCNA analysis and keeping in mind that the expression of PCNA is regulated at several levels within the cell (Figure 1), the questions need to be answered as to how and which genotoxic, mitogenic, and cytotoxic compounds (Figure 12), hormones, and growth factors influence not only the expression of PCNA, but also the stability/half-life of PCNA mRNA and its protein product and thus the reliability of PCNA as a cell proliferation marker.

Such questions may be addressed by using a well-defined cell system, i.e., a cell line with a well-characterized and manipulatable cell cycle such as the Chinese hamster ovary cell, the V79 chinese hamster lung fibroblast, ${ }^{146}$ or T lymphocytes, ${ }^{4.3}$ and combining flow cytometry, immunocytochemistry, and biochemical techniques (Western blot analysis, etc.) for PCNA analysis. Furthermore, these experiments should focus not only on the PCNA gene, mRNA, and gene product, but also on PCNA regulating factors such as p53, p105(Rb), and TGF- $\beta$ (Figure 6), thus distinguishing between direct and indirect effects of compounds on PCNA expression. Indeed, with the development of techniques such as PCR and the availability of cDNA probes for rat and human PCNA, 5,6,21 it should be possible to analyze compound-induced alterations in the PCNA gene. Using these techniques, Liu and Bambara ${ }^{54}$ demonstrated that PCNA is overexpressed in the R3230AC mammary tumor, which was accompanied by an altered PCNA gene structure. In addition, the experiments proposed earlier should be able to demonstrate whether an increased expression of PCNA is associated with replicative DNA synthesis or DNA excision repair (Figures 2 and 3). Although in vitro experiments, such as the ones proposed previously, are helpful in understanding the effects of compounds on a specific cell subpopulation of the cell cycle, they cannot replace studies in a whole tissue. Indeed, this is demonstrated by the study of Foley and co-workers, ${ }^{125}$ who found higher S-phase PCNA $\mathrm{LI}$ in liver foci of alteration than in the surrounding normal hepatocytes of control and methylene chloride-exposed female $\mathrm{B} 6 \mathrm{C} 3 \mathrm{~F} 1$ mice, thus demonstrating a higher proliferative rate in the clonally expanded preneoplastic lesions. However, the combination of in vitro experiments with retrospective cell proliferation measurements in archival tissues of completed studies 
provides a powerful tool for studying the toxicity and/or carcinogenicity of the respective compounds. Furthermore, recent progress made in flow-cytometric analysis of archival tissues should allow distinguishing between PCNA associated with replicative DNA synthesis and PCNA involved in DNA excision repair, thus providing better insight into cell proliferation mechanisms and higher reliability of cell proliferation measurements.

Also, additional studies, e.g., analyzing cell proliferation measurement variability resulting from fixation, tissue handling, antibody, and staining procedure related effects, are required for the proper utilization and interpretation of the cell proliferation response as detected by PCNA analysis. Provided these studies are carried out and result in an improvement of in the methodology and a better data base, PCNA immunohistochemistry may prove to be the method of choice not only for retrospective but also for prospective studies. In view of recent reports regarding the adverse effects of the well-established cell proliferation marker BrdU, which suggest that BrdU may be toxic and therefore enhances the cell proliferative response, ${ }^{163,164}$ these studies are urgently needed. Although most studies reported so far have been conducted in rodents and humans, PCNA immunohistochemistry and cytochemistry allow cell proliferation and cell cycle analysis to be conducted in a multitude of other organisms ${ }^{7,8,10-12,133}$ with the benefit that the findings all have the same denominator and thus are readily comparable. This also should make it possible to transfer the knowledge on toxic and carcinogenic mechanisms obtained in mammals to non-mammalian organisms important as bioindicators, such as fish or clams, for ecotoxicological risk assessment.

\section{B. Surgical Pathology/Modern Medicine}

The quest for more efficient management of patients afflicted with neoplasia and efforts to better predict the progression of tumors have led to a rather uncritical use of so-called prognostic markers in human tumors. Indeed, in many cases, such markers were readily applied without a clear understanding of the role or function of the marker in the respective tumor. ${ }^{165}$ PCNA immunohistochemistry has been called upon as a means for estimating the growth fraction ${ }^{136,154,155}$ within a given tumor as well as a means for trying to predict the progression of tumors based on the perhaps naive assumption that a high degree of PCNA staining reflects high proliferative activity per se and thus automatically means a worse prognosis for the patient, irrespective of the tumor type. ${ }^{129,130,160}$ Although the PI assessed via PCNA immunohistochemistry appears to have a prognostic value in hemangiopericytomas, ${ }^{143}$ gastric carcinomas, ${ }^{153}$ gastrointestinal lymphomas, ${ }^{152}$ colorectal cancer, ${ }^{102}$ soft tissue sarcomas, ${ }^{166}$ and melanomas, ${ }^{1.36}$ this was not the case in ovarian cancer, ${ }^{167}$ acute myelogenous leukemia, ${ }^{74}$ and, in contrast to the findings by Takahashi et al., ${ }^{136}$ in melanomas with 8 or more years of clinical follow-up (Figure 11). ${ }^{34,135}$ Woosely and co-workers ${ }^{134,135}$ statistically correlated the prognostic value of the proliferative fraction estimated via PCNA in melanomas with the clinical outcome (patient survival) and other prognostic indicators, e.g., anatomical level, tumor thickness, mitotic frequency, tumor infiltrating lymphocytes, tumor regression, or sex, and demonstrated that PCNA did not correlate to either the clinical outcome or any of the other prognostic indicators. Takahashi et al. ${ }^{136}$ on the other hand, compared the growth fraction visualized via PCNA immunohistochemistry with tumor grade only and found that PCNA-positive tumor cells increased in number and staining intensity with increasing progression of the lesions toward malignancy. To further understand the role of PCNA in melanomas, they exposed normal skin to sunlight, found that mainly suprabasal keratinocytes stained positive for PCNA whereas melanocytes were PCNA negative, and concluded that PCNA-positive staining in melanocytes was closely associated with malignant transformation. At first sight, the results of the studies by Woosley and co-workers ${ }^{134}$ and Takahashi and co-workers ${ }^{136}$ seem to contradict one another, but this need not necessarily be the case. The main problem lies in the assumption that all positive PCNA staining is associated with replicating activity; however, PCNA expression may be altered by changes in the structure of the PCNA gene, as was already shown to be the case in rat mam- 
mary tumors, ${ }^{54}$ and potentially has nothing to do with increased cell proliferation. Furthermore, increased PCNA-positive staining clearly not associated with cell proliferation also was observed in patients with acute myelogenous leukemia in conjunction with increased resistance to chemotherapy ${ }^{74}$ in which case this increased PCNA expression was attributed to enhanced DNA excision repair. Indications of the latter observation also can be found in the study by Takahashi and co-workers ${ }^{136}$ in that presumably increased cell proliferation-associated PCNA staining was observed in keratinocytes of the suprabasal layer but not in the basal layer of normal skin exposed to sunlight, although it is known that the basal cell layer is proliferatively active, thus indicating that some of the PCNA reactivity observed may have been due to DNA excision repair demonstrated to occur in cells irradiated with UV light (see Section IV.B). ${ }^{69,168}$ Therefore, PCNA immunostaining in melanomas may reflect a cohort of several "PCNA populations:" PCNA expressed as a function of cell replication, PCNA redistributed as a function of DNA excision repair, and PCNA over/underexpressed due to an alteration in the PCNA gene or deregulated PCNA transcription and translation. Deregulated PCNA transcription or translation also was suggested in cases where increased immunohistochemically detectable PCNA was observed in histopathologically normal breast lobules adjacent to breast tumors as well as in pancreatic exocrine parenchyma adjacent to endocrine and exocrine tumors of the pancreas. ${ }^{45}$ In these cases, it was postulated that some of the tumors are actively secreting growth factors that are stabilizing the PCNA mRNA and thus inducing PCNA protein accumulation without actually inducing DNA synthesis. In this context, it also would be useful to analyze whether deregulated PCNA expression could stem from structural changes in the PCNA gene in these tumors, as was shown to be the case in rat mammary tumors. ${ }^{54} \mathrm{~A}$ further solution to this dilema may be the use of retrospective flow cytometry in conjunction with PCNA immunohistochemistry, thus distinguishing proliferating from nonproliferating cell populations. This approach was chosen by Woods and coworkers ${ }^{152}$ in their evaluation of PCNA immunohistochemistry in primary gastrointestinal lym- phomas. Their study showed that there is a good correlation between the PCNA index and the histological grade of the tumors as well as a significant relationship between the PCNA index and the $\mathrm{S}+\mathrm{G} 2+\mathrm{M}$-phase fraction as measured by retrospective flow-cytometric analysis. A high PCNA index was significantly correlated with poor patient survival, thus indicating that a high PCNA index is an adverse prognostic factor in primary gastrointestinal tumors. Using the same approach, Jain and co-workers ${ }^{153}$ and Yu et al. ${ }^{143}$ evaluated the prognostic value of PCNA in gastric carcinomas and hemangiopericytomas, respectively. Although it was demonstrated that the PCNA index correlated well with patient survival probability in both retrospective studies, a positive correlation between PCNA index and histological grade was demonstrated only in hemangiopericytomas. In gastric carcinomas, the PCNA index did not correlate with histological grade, nor was there any correlation between PCNA index and tumor stage or lymph node metastasis. Furthermore, in both tumor types, the comparison between flow-cytometric measurement of cell proliferation and PCNA index, histological grade, or patient survival revealed that the results obtained with flow cytometry did not correlate with any of the latter parameters. Autocrine and paracrine growth factor-mediated regulation of PCNA expression also may explain the excess of PCNA immunoreactive cells observed in the above-mentioned tumors, indicating that not all PCNA staining observed in the different tumor types is functionally associated with cell replication, ${ }^{160}$ thus emphasizing that PCNA immunohistochemistry in conjunction with retrospective flow cytometry may be a helpful tool for understanding tumor etiology and progression, but that the PCNA index should not be uncritically used as a prognostic marker.

PCNA immunohistochemistry also has been used to visualize regenerating hepatocytes in patients with acute viral hepatitis, hepatic cirrhosis, or hepatocellular carcinomas, ${ }^{169}$ and to measure cell proliferation in hyperplastic, preneoplastic, and neoplastic lesions of intrahepatic bile ducts in livers with hepatoliths. ${ }^{170}$ In the former study, the respective lesions were characterized by lesion-specific PCNA staining patterns and proliferation rates, while in the latter study it was shown 
that the PCNA LI increased with increasing malignant progression of the lesion, i.e., lowest in hyperplasias and highest in invasive adenocarcinomas. Simultaneous determination of the mean number of argyrophylic nucleolar organizer regions (AgNORs) demonstrated a significant positive correlation between PCNA LI and AgNORs count in all lesions, ${ }^{170}$ thus suggesting that PCNA immunohistochemistry can be used for cell proliferation measurement in certain human tissues and lesions.

\section{SUMMARY}

The cell cycle-associated protein PCNA was reviewed here with regard to its regulation, expression, and function during the cell cycle as well as its use as a proliferation marker in toxicology and pathology and as a prognostic indicator in surgical pathology, i.e., patient management, particularly those afflicted with neoplasia. Despite numerous studies analyzing the function of PCNA in the cell, only two functions have been clearly elucidated to date, its association with replicative DNA synthesis and with DNA excision repair. Due to the varying expression levels and the varying distribution (localization) of PCNA during the cell cycle, it may be hypothesized that PCNA could have other functions besides the ones stated above. Future studies should focus on determining whether or not such additional functions exist. Moreover, additional studies are required that will provide data on the regulation/deregulation of PCNA expression by chemicals, hormones, growth factors, protooncogenes, and tumor suppressor genes. Only then will it be possible to adequately interprete the experimental data that used PCNA as a proliferation marker either by immunohistochemistry, immunocytochemistry, or flow cytometry. Furthermore, it will be necessary to understand and to be able to distinguish methodological effects related to tissue treatment, fixation, storage, and staining from compound-related effects on PCNA expression. However, despite these caveats, the present data clearly demonstrate that PCNA can be used for cell proliferation measurements in prospective as well as in retrospective studies. A more critical approach must be taken for the use of PCNA as a prognostic marker in human tumors. The high variability of PCNA staining observed within tumors and among different tumor types limits its use as a prognostic marker per se for many tumor types. However, additional clinicopathological studies, whether prospective or retrospective, that encompass excellent patient selection, large numbers of patients, multiparameter analysis, documented clinical outcome, and comparable patient treatment protocols should be able to elucidate the role of PCNA in the context of human disease.

\section{ACKNOWLEDGMENTS}

I would like to thank Dr. Christian Sengstag and Prof. Fritz Würgler for critically reviewing the manuscript and Nicola Wittekindt for helpful comments regarding the illustrations.

\section{REFERENCES}

1. Miyachi, K., Fritzler, M. J., and Tan, E. M., Autoantibody to a nuclear antigen in proliferating cells, J. Immunol., 121(6), 2228, 1978.

2. Doolittle, D. J., McKarns, S. C., Ayres, P. H., and Bombick, D. W., Molecular approaches for quantifying DNA synthesis and cell proliferation during rodent bioassays, Toxicol. Methods, 1(4), 215 , 1991.

3. Ogata, K., Kurki, P., Celis, E. J., Nakamura, R. M., and Tan, E. M., Monoclonal antibodies to a nuclear protein (PCNA/cyclin) associated with DNA replication, Exp. Cell. Res., 168, 475, 1987.

4. Almendral, J. M., Heubsch, D., Blundell, P. A., MacDonald-Bravo, H., and Bravo, R., Cloning and sequence of the human nuclear protein cyclin: Homology with DNA-binding proteins, Proc. Natl. Acad. Sci. U.S.A., 84, 1575, 1987.

5. Moriuchi, T., Matsumoto, K., Koji, T., and Nakane, P. K., Molecular cloning and nucleotide sequence analysis of rat PCNA/cyclin cDNA, Nucleic Acids Res., 17, 117, 1986.

6. Matsumoto, K., Moriuchi, T., Koji, T., and Nakane, P. K., Molecular cloning of cDNA coding for rat proliferating cell nuclear antigen (PCNA/cyclin), EMBO J., 6(3), 637, 1987.

7. Zuber, M., Tan, E. M., and Ryoji, M., Involvement of proliferating cell nuclear antigen (cyclin) in 
DNA replication in living cells, Mol. Cell. Biol., 9(1), 57, 1989.

8. Zuber, M., Yasui, W., Tan, E. M., and Ryoji, M., Quantitation and subcellular localization of proliferating cell nuclear antigen (PCNA) in oocytes and eggs of Xenopus laevis, Exp. Cell Res., 182, 384, 1989.

9. Celis, J. E., Madsen, P., Celis, A., Nielsen, H. V., and Gesser, B., Cyclin (PCNA, auxiliary protein of DNA polymerase $\delta$ ) is a central component of the pathway(s) leading to DNA replication and cell division, FEBS Lett., 220(1), 1, 1987.

10. Yamaguchi, M., Nishida, Y., Moriuchi, T., Hirose, F., Hui, C., Suzuki, Y., and Matsutake, A., Drosophila proliferating cell nuclear antigen (cyclin) gene: structure, expression during development, and specific binding of homeodomain proteins to its 5 -flanking region, Mol. Cell. Biol., 10(3), 872, 1990.

11. Olins, D. E., Olins, A. L., Cacheiro, L. H., and Tan, E. M., Proliferating cell nulcear antigen/cyclin in ciliate Euplotes eurystemus: localization in the replication band and micronuclei, J. Cell Biol., 109, 1399, 1989.

12. Suzuka, I., Daidoji, H., Matsuoka, M., Kadowaki, K., Takasaki, Y., Nakane, P. K., and Moriuchi, T., Gene for proliferating cell nuclear antigen (DNA polymerase $\delta$ auxiliary protein) is present in both mammalian and higher plant genomes, Proc. Natl. Acad. Sci. U.S.A., 86, 3189, 1989.

13. Bauer, G. A. and Burger, P. M. J., The yeast analog of mammalian cyclin/proliferating cell nuclear antigen interacts with mammalian DNA polymerase 6, Proc. Natl. Acad. Sci. U.S.A., 85, 7506, 1988.

14. O'Reilly, D. R., Crawford, A. M., and Miller, L. K., Viral proliferating cell nuclear antigen, Nature, 337, 606, 1989

15. Hori, H. and Osawa, S., Evolutionary change in 5S RNA secondary structure and a phylogenic tree of 545 S RNA species, Proc. Natl. Acad. Sci. U.S.A., 76(1), 381, 1979 .

16. Kimura, M. and Ohta, T., On some principles governing molecular evolution, Proc. Natl. Acad. Sci. U.S.A., 71(7), $2848,1974$.

17. Yamaguchi, M., Hayashi, Y., Hirose, F., Matsuka, S., Moriuchi, T., Shiroishi, T., Moriwaki, K., and Matsukage, A., Molecular cloning and structural analysis of mouse gene and pseudogenes for proliferating cell nuclear antigen, Nucleic Acids Res., 19(9), 2403,1991

18. Kosugi, S., Suzuka, I., Ohashi, Y., Marakami, T., and Arai, Y., Upstream sequences of rice proliferating cell nuclear antigen (PCNA) gene mediate expression of PCNA-GUS chimeric gene in meristems of transgenic tobacco plants, Nucleic Acids Res., 19(7), 1571, 1991.

19. Desplan, C., Theis, J., and O'Farrell, P. H., The sequence specificity of homeodomain-DNA interaction, Cell, 54, 1081, 1988.

20. Chowdhury, K., Deutsch, U., and Gruss, P., A multigene family encoding several "finger" struc- tures is present and differentially active in mammalian genomes, Cell, 48, 771, 1987.

21. Travali, S., Ku, D.-H., Rizzo, M.-G., Ottavio, L., Baserga, $\mathbb{R}$., and Calabretta, B., Structure of the human gene for the proliferating cell nuclear antigen, J.Biol. Chem., 264(13), 7466, 1989.

22. Ottavio, L., Chang, C.-D., Rizzo, M.-G., Travali, S., Casadevali, C., and Baserga, R., Importance of introns in the growth regulation of mRNA level of the proliferating cell nuclear antigen, $\mathrm{Mol}$. Cell. Biol., 10(1), 303, 1990.

23. Takasaki, Y., Fishwild, D., and Tan, E. M., Characterization of proliferating cell nuclear antigen recognized by autoantibodies in lupus sera, J. Exp. Med., $159,981,1984$

24. Laughon, A. and Scott, M. P., Sequence of a Drosophila segmentation gene: protein structure homology with DNA-binding proteins, Nature, 310, 25, 1984.

25. Tan, C.-K., Castillo, C., So, A. G., and Downey, K. M., An auxiliary protein for DNA polymerase $\delta$ from fetal calf thymus, J. Biol. Chem., 261(26), $12310,1986$.

26. Ogata, K., Celis, J. E., and Tan, E. M., Proliferating cell nuclear antigen: cyclin, Methods Enzymol., 150, 147, 1987.

27. Celis, J. E., Bravo, R., Larsen, P. M., and Fey, S., Cyclin: a nuclear protein whose level correlates directly with the proliferative state of normal as well as transformed cells, Leukemia Res., 8(2), 143, 1984.

28. Bravo, R., Frey, S. J., Bellantin, J., Larsen, P. M., Arevalo, J., and Celis, J. E., Identification of a nuclear and of a cytoplasmic polypeptide whose relative proportions are sensitive to changes in the rate of cell proliferation, Exp. Cell. Res., 136, 311, 1981.

29. Mathews, M. B., Bernstein, R. M., Franza, B. R., and Garrels, J. I., Identity of the proliferating cell nuclear antigen and cyclin, Nature, 309, 374, 1984.

30. Sadaie, M. R. and Mathews, M. B., Immunochemical and biochemical analysis of the proliferating cell nuclear antigen (PCNA) in HeLa cells, Exp. Cell. Res., 163, 423, 1986.

31. Smart, J. E., Lewis, J. B., Mathews, M. B., Harter, M. L., and Anderson, C. W., Adenovirus type 2 early proteins: assignment of the early region $1 \mathrm{~A}$ proteins synthesized in vivo and in vitro to specific mRNAs, Virology, 112, 703, 1981.

32. Persson, H., Hennighausen, L., Taub, R., DeGrado, W., and Leder, P., Antibodies to human c-myc oncogene product: evidence of an evolutionary conserved protein induced during cell proliferation, Science, 225, 687, 1984.

33. Prelich, G., Kostura, M., Marshak, D. R., Mathews, M. B., and Stillman, B., The cell-cycle regulated proliferating cell nuclear antigen is required for SV40 DNA replication in vitro, Nature, 326, 471, 1987.

34. Bauer, G. A. and Burgers, P. M. J., Molecular cloning, structure and expression of the yeast prolif- 
erating cell nuclear antigen gene, Nucleic Acids Res., 18(2), 261, 1990.

35. Bravo, R. and MacDonald-Bravo, H., Changes in the nuclear distribution of cylin (PCNA) but not its synthesis depend on DNA replication, EMBO J., 4(3), 655,1985 .

36. Bravo, R. and MacDonald-Bravo, $\mathbb{H}$., Existence of two populations of cyclin/proliferating cell nuclear antigen during the cell cycle: association with DNA replication sites, J. Cell Biol., 105, 1549, 1987.

37. Celis, J. E., Fey, S. J., Larsen, P. M., and Celis, A., Expression of the transformation-sensitive protein "cyclin" in normal human epidermal basal cells and simian virus 40-transformed keratinocytes, Proc. Natl. Acad. Sci. U.S.A., 81, 3128, 1984.

38. Celis, J. E. and Celis, A., Cell cycle-dependent variations in the distribution of the nuclear protein cyclin proliferating cell nuclear antigen in cultured cells: subdivision of S phase, Proc. Natl. Acad. Sci. U.S.A., 82, 3262, 1985.

39. Celis, J. E. and Madsen, P., Increased nuclear cyclin/PCNA antigen staining of non S-phase transformed human amnion cells engaged in nucleotide excision DNA repair, FEBS Lett., 209(2), 277, 1986.

40. Kurki, P., Vanderlaan, M., Dolbeare, F., Gray, J., and Tan, E. M., Expression of proliferating cell nuclear antigen (PCNA/cyclin) during the cell cycle, Exp. Cell. Res., 166, 209, 1986.

41. Kurki, P., Ogata, K., and Tan, E. M., Monoclonal antibodies to proliferating cell nuclear antigen (PCNA) cyclin) as probes for proliferating cells by immunofluorescence microscopy and flow cytometry, J. Immunol. Methods., 109, 49, 1988.

42. Jaskulski, D., Gatti, C., Travali, S., Calabretta, B., and Baserga, R., Regulation of the proliferating cell nuclear antigen cyclin and thymidine kinase mRNA levels by growth factors, J. Biol. Chem., 263(21), 10175, 1988.

43. Kurki, P., Lotz, M., Ogata, K., and Tan, E. M., Proliferating cell nuclear antigen (PCNA)/cyclin in activated human $\mathrm{T}$ lymphocytes, $J$. Immunol., 138(12), 4114, 1987.

44. Morris, G. F. and Mathews, M. B., Regulation of proliferating cell nuclear antigen during the cell cycle, J. Biol. Chem., 264(23), 13856, 1989.

45. Hall, P. A., Levinson, D. A., Woods, A. L., Yu, C. C.-W., Kellock, D. B., Watkins, J. A., Barnes, D. M., Gillett, C. E., Camplejohn, R., Dover, R., Waseem, N. H., and Lane, D. P., Proliferating cell nuclear antigen (PCNA) immunolocalization in paraffin sections: an index of cell proliferation with evidence of deregulated expression in some neoplasms, J. Pathol., 162, 285, 1990.

46. Ogata, K., Ogata, Y., Takasaki, Y., and Tan, E. M., Epitopes on proliferating cell nuclear antigen recognized by human lupus autoantibody and murine monoclonal antibody, J. Immunol., 139(9), 2942, 1987.

47. Ogata, K., Ogata, Y., Nakamura, R. M., and Tan, E. M., Purification and $\mathrm{N}$-terminal amino acid se- quence of proliferating cell nuclear antigen (PCNA)/ cyclin and development of ELISA for anti-PCNA antibodies, J. Immunol., 135(4), 2623, 1985.

48. Waseem, N. H. and Lane, D. P., Monoclonal antibody analysis of the proliferating cell nuclear antigen (PCNA): structural conservation and the detection of a nucleolar form, J. Cell Sci., 96, 121, 1990.

49. Richter, F., Richter, A., Yang, K., and Lipkin, M., Cell proliferation in rat colon measured with BrdU, PCNA, and [ $\left.{ }^{3} \mathrm{H}\right] \mathrm{dThd}$, Proc. Am. Assoc. Cancer Res., 32, 154, 1991.

50. Galand, P. and Degraef, C., Cyclin/PCNA immunostaining as an alternative to triated thymidine pulse labeling for marking S-phase cells in paraffin sections from animal and human tissues, Cell Tissue Kinet., 22, 383, 1989.

51. Coltrera, M. D. and Gown, A. M., PCNA/Cyclin expression and BrdU uptake define different subpopulations in different cell lines, J. Histochem. $C y$ tochem., 39(1), 23, 1991.

52. Baserga, R., Growth regulation of the PCNA gene, J. Cell Sci., 98, 433, 1991.

53. Chang, C.-D., Ottavio, L., Travali, S., Lipson, K., and Baserga, R., Transcriptional and posttranscriptional regulation of the proliferating cell nuclear antigen gene, Mol. Cell. Biol., 10(7), 3289, 1990.

54. Liu, Y.-C. and Bambara, R. A., Gene expression of PCNA/cyclin in adult tissues and the R3230AC mammary tumor of the rat, Biochem. Biophys. Res. Commun., 161(2), 873, 1989.

55. Wong, R. L., Katz, M. E., Ogata, K., Tan, E. M., and Cohen, S., Inhibition of nuclear DNA synthesis by an autoantibody to proliferating cell nuclear antigen/cyclin, Cell. Immunol., 110, 443, 1987.

56. Jaskulski, D., de Riel, J. K., Mercer, W. E., Calabretta, B., and Baserga, R., Inhibition of cellular proliferation by antisense oligodeoxynucleotides to PCNA/cyclin, Science, 240, 1544, 1988.

57. Bravo, R., Frank, R., Blundell, P. A., and MacDonald-Bravo, H., Cyclin/PCNA is the auxiliary protein of DNA polymerase $\delta$, Nature, 326,515 , 1987.

58. Prelich, G., Tan, C.-K., Kostura, M., Mathews, M. B., So, A. G., Downey, K. M., and Stillman, B., Functional identity of proliferating cell nuclear antigen and DNA polymerase $\delta$ auxiliary protein, Nature, 326, 517, 1987.

59. Wolds, M. S., Li, J. J., Weinberg, D. H., Virshup, D. M., Sherley, J. L., Verheyen, E., and Kelly, T., Cellular proteins required for SV40 DNA replication in vitro, Cancer Cells, 6, 133,1988.

60. Fairman, M. P., DNA polymerase $\delta / P C N A$ : actions and interactions, J. Cell Sci., 95, 1, 1990.

61. Downey, K. M., Tan, C.-K., Andrews, D. M., Li, X., and So, A. G., Proposed roles for DNA polymerases $\alpha$ and $\delta$ at the replication fork, Cancer Cells, 6, 403, 1988.

62. So, A. G. and Downey, K. M., Mammalian DNA polymerases $\alpha$ and $\delta$ : current status in DNA replication, Biochemistry, 27(13), 4591, 1988. 
63. Stillman, B., Initiation of eukaryotic DNA replication in vitro, BioEssays, 9, 56, 1988.

64. Prelich, G. and Stillman, B., Coordinated leading and lagging strand synthesis during SV40 DNA replication in vitro requires PCNA, Cell, 53, 117, 1988.

65. Tsurimoto, T. and Stillman, B., Replication factors required for SV40 DNA replication in vitro. $I, J$. Biol. Chem., 266(3), 1950, 1991.

66. Tsurimoto, T. and Stillman, B., Replication factors required for SV40 DNA replication in vitro. II, $J$. Biol. Chem., 266(3), 1961, 1991.

67. Melendy, T. and Stillman, B., Purification of DNA polymerase $\delta$ as an essential simian virus 40 DNA replication factor, J. Biol. Chem., 266(3), 1942, 1991.

68. Lee, S.-H., Kwong, A. D., Pan, Z.-Q., and Hurwitz, J., Studies on the activator 1 protein complex, an accessory factor for proliferating cell nuclear antigen-dependent polymerase $\delta, J$. Biol. Chem., 266(1), 549, 1991 .

69. Toschi, L. and Bravo, R., Changes in cyclin/proliferating cell nuclear antigen distribution during DNA repair synthesis, J. Cell Biol., 107, 1623, 1988.

70. Shivji, M. K. K., Kenny, M. K., and Wood, R. D., Proliferating cell nuclear antigen is required for DNA excision repair, Cell, 69, 367, 1992.

71. Coverley, D., Kenny, M. K., Lane, D. P., and Wood, R. D., A role for the human single-stranded DNA binding protein HSSB/RPA in an early stage of nucleotide excision repair, Nucleic Acids Res., 20(15), 3873, 1992.

72. Syvaoja, J. and Linn, S., Characterization of a large form of DNA polymerase $\delta$ from HeLa cells that is insensitive to proliferating cell nuclear antigen, $J$. Biol. Chem., 264(5), 2489, 1989.

73. Nishida, C., Reinhard, P., and Linn, S., DNA repair synthesis in human fibroblasts requires DNA polymerase $\delta, J$. Biol. Chem., 263(1), 501, 1989.

74. del Giglio, A., Khetan, R., Saya, H., Johnston, D., Hester, J., El-Naggar, A., and Deisseroth, A., High levels of PCNA in adult acute myelogenous leukemia (AML) are associated to increased resistance to chemotherapy and not to cell proliferation, Proc. Am. Assoc. Cancer Res., 33, 1589, 1992.

75. Finlay, C. A., Hinds, P. W., and Levine, A. J., The p53 proto-oncogene can act as a suppressor of transformation, Cell, 57, 1083, 1989.

76. Mercer, W. E., Shields, M. T., Amin, M., Sauve, G. J., Appella, E., Romano, J. W., and Ullrich, S. J., Negative growth regulation in a glioblastoma tumor cell line that conditionally expresses human wild-type p53, Proc. Natl. Acad. Sci. U.S.A., 87, 6166, 1990.

77. Levine, A. J., Momad, J., and Finlay, C. A., The p53 tumor suppressor gene, Nature, 351, 453, 1991.

78. Marshall, D. J., Tumor suppressor genes, Cell, 64, 313,1991 .

79. Harlow, E., For our eyes only, Nature, 359, 270, 1992.

80. Buchkovich, K., Duffy, L. A., and Harlow, E., The retinoblastoma protein is phosphorylated during specific phases of the cell cycle, Cell, 59, 1097, 1989.

81. Mihara, K., Cao, X.-R., Yen, A., Chandler, S., Discroll, B., Murphree, L., T'Ang, A., and Fung, Y.-K. T., Cell cycle-dependent regulation of phosphorylation of the human retinoblastoma gene product, Science, 246, 1300, 1989.

82. DeCaprio, J. A., Ludlow, J. W., Lynch, D., Furukawa, Y., Griffin, J., Piwnica-Worms, H., Huang, C.-M. , and Livingston, D. M., The product of the retinoblastoma susceptibility gene has properties of a cell cycle regulatory element, Cell, 58, 1085, 1989.

83. Chen, P.-L., Scully, P., Shew, J.-Y., Wang, J. Y. J., and Lee, W.-H., Phosphorylation of the retinoblastoma gene product is modulated during the cell cycle and cellular differentiation, Cell, 58, 1193, 1989.

84. Bischoff, J. R., Friedman, P. N., Marshak, D. R., Prives, C., and Beach, D., Human p53 is phosphorylated by p60-cdc2 and cyclin B-cdc2, Proc. Natl. Acad. Sci. U.S.A., 87, 4766, 1990.

85. Hunter, T. and Pines, J., Cyclins and cancer, Cell, 66, 1071, 1991.

86. Kern, S. E., Kinzler, K. W., Bruskin, A., Jarosz, D., Friedman, P., Prives, C., and Vogelstein, B., Identification of $\mathrm{p} 53$ as a sequence-specific DNAbinding protein, Science, 252, 1078, 1991.

87. Fields, S. and Jang, S. K., Presence of a potent transcription activating sequence in the $\mathrm{p} 53$ protein, Science, 249, 1046, 1990.

88. Raycroft, L., Wu, H., and Lozano, G., Transcriptional activation by wild-type but not transforming mutants of the p53 anti-oncogene, Science, 249, 1049, 1990.

89. Lee, W.-H., Shew, J.-S., Hong, F. D., Sery, T. W., Donoso, L. A., Young, L.-J., Bookstein, R., and Lee, E. Y.-H. P., The retinoblastoma susceptibility gene encodes a nuclear phosphoprotein associated with DNA binding activity, Nature, 329, 642, 1987.

90. Mercer, W. E., Shields, M. T., Lin, D., Appella, E., and Ullrich, S. J., Growth suppression induced by wild-type $\mathrm{p} 53$ protein is accompanied by selective down-regulation of proliferating cell nuclear antigen expression, Proc. Natl. Acad. Sci. U.S.A., 88, 1958, 1991.

91. Kastan, M. B., Onyekwere, O., Sidransky, D., Vogelstein, B., and Craig, R. W., Participation of p53 protein in the cellular response to DNA damage, Cancer Res., 51, 6304, 1991.

92. Gannon, J. V., Greaves, R., Iggo, R., and Lane, D. P., Activating mutations in $\mathrm{p} 53$ produce a common conformational effect. A monoclonal antibody specific for the mutant form, EMBO J., 9(5), 1595, 1990.

93. Koniecki, J., Nugent, P., Kordowska, J., and Baserga, R., Effect of the SV40 T antigen on the posttranscriptional regulation of the proliferating cell nuclear antigen and DNA polymerase- $\alpha$ genes, Cancer, Res., 51, 1465, 1991. 
94. Lane, D. P. and Crawford, L. V., T antigen is bound to a host protein in SV 40-transformed cells, Nature, 278, 261, 1979.

95. Horowitz, J. M., Yandell, D. W., Park, S.-H., Canning, S., Whyte, P., Buchkovich, K., Harlow, E., Weinberg, R. A., and Dryja, T. P., Point mutational inactivation of the retinoblastoma antioncogene, Science, 243, 937, 1989.

96. DeCaprio, J. A., Ludlow, J. W., Figge, J., Shew, J.-Y., Huang, C.-M., Lee, W.-H., Marsilio, E., Paucha, E., and Livingston, D. M., SV40 large tumor antigen forms a specific complex with the product of the retinoblastoma susceptibility gene, Cell, 54, 275, 1988.

97. Pietenpol, J. A., Holt, J. T., Stein, R. W., and Moses, H. L., Transforming growth factor $\beta 1$ suppression of c-myc gene transcription: role in inhibition of keratinocyte proliferation, Proc. Natl. Acad. Sci. U.S.A., 87, 3758, 1990.

98. Pietenpol, J. A., Stein, R. W., Moran, E., Yaciuk, P., Schlegel, R., Lyons, R. M., Pittelkow, M. R., Münger, K., Howley, P. M., and Moses, H. L., TGF- $\beta 1$ inhibition of c-myc transcription and growth in keratinocytes is abrogated by viral transforming proteins with pRB binding domains, Cell, 61, 777, 1990.

99. Stanbridge, E. J., Human tumor suppressor genes, Annu. Re'v. Genet., 24, 615, 1990.

100. Jelsma, T. N., Howe, J. A., Mymryk, J. S., Evelegh, C. M., Cunniff, N. F. A., and Bayley, S. T., Sequences in ElA proteins of human adenovirus 5 required for cell transformation, repression of a transcriptional enhancer, and induction of proliferating cell nuclear antigen, Virology, 171, 120 1989.

101. Morris, G. F. and Mathews, M. B., The adenovirus E1A transforming protein activates the proliferating cell nuclear antigen promoter via an activating transcription factor site, J. Virol., 65(12), 6397, 1991.

102. Darmon, E. and Wargovich, M. J., Immunohistochemical detection of p53 and PCNA overexpression in colorectal tumors, Proc. Am. Assoc. Cancer Res., 33, 1712, 1992.

103. Nicholas, J., Cameron, K. R., and Honess, R. W., Herpesvirus saimiri encodes homologues of $G$ protein-coupled receptors and cyclins, Nature, 355, 362, 1992.

104. Swenson, K. I., Farrell, K. M., and Ruderman, J. V., The clam embryo protein cyclin A induces entry into $M$ phase and the resumption of meiosis in Xenopus oocytes, Cell, 47, 861, 1986.

105. Dunphy, W. G. and Newport, J. W., Unraveling of mitotic control mechanisms, Cell, 55, 925, 1988.

106. Evans, T., Rosenthal, E. T., Youngblom, J., Distel, D., and Hunt, T., Cyclin: a protein specified by maternal mRNA in sea urchin eggs that is destroyed at each cleavage division, Cell, 33, 389, 1983.

107. Pines, J. and Hunt, T., Molecular cloning and characterization of the mRNA for cyclin from sea urchin eggs, EMBO J., 6(10), 2987, 1987.
108. Booher, R. and Beach, D., Involvement of cdc $13^{+}$ in mitotic control in Schizosaccharomyces pombe: possible interaction of the gene product with microtubules, EMBO J., 7(8), 2321, 1988.

109. Solomon, M., Booher, R., Kirschner, M., and Beach, D., Cyclin in fission yeast, Cell, 54, 738, 1988.

110. Murray, A. W. and Kirschner, M. W., Dominoes and clocks: the union of two views of the cell cycle, Science, 246, 614, 1989.

111. Pines, J. and Hunter, T., Isolation of a human cyclin cDNA: evidence for cyclin mRNA and protein regulation in the cell cycle and for interaction with p34 cle? Cell, 58, 833, 1989.

112. Lu, X. P., Koch, K. S., Lew, D. J., Dulic, V., Pines, J., Reed, S. I., Hunter, T., and Leffert, H. L., Induction of cyclin mRNA and cyclin-associated histone $\mathrm{H} 1$ kinase during liver regeneration, J. Ciol. Chem., 267(5), 2841, 1992.

113. Murray, A. W. and Kirschner, M. W., What controls the cell cycle?, Sci. Am., 264(3), 34, 1991.

114. Girard, F., Strausfeld, U., Fernandez, A., and Lamb, N. J. C., Cyclin A is required for the onset of DNA replication in mammalian fibroblasts, Cell, $67,1169,1991$.

115. Devoto, S. H., Mudryi, M., Pines, J., Hunter, T., and Nevins, J., A cyclin A-protein kinase complex possesses sequence-specific DNA binding activity: p33 $3^{\text {clck }}$ is a component of the E2F-cyclin A complex, Cell, 68, 167, 1992.

116. Ames, B. N., Profet, M., and Gold, L. S., Nature's chemicals and synthetic chemicals: comparative toxicology, Proc. Natl. Acad. Sci. U.S.A., 87, 7782, 1990.

117. Moolgavkar, S. H. and Leubeck, G., Two-event model carcinogenesis: biological, mathematical, and statistical considerations, Risk Anal., 10(2), 323, 1990.

118. Cohen, S. M. and Ellwein, L. B., Cell proliferation in carcinogenesis, Science, 249 1007, 1990.

119. Goldsworthy, T. L., Butterworth, B. E., and Maronpot, R. R., Concepts, labeling procedures, and design of cell proliferation studies relating to carcinogenesis, Environ. Health Perspect., in press.

120. Dietrich, D. R. and Swenberg, J. A., The presence of $\alpha_{2 \mu}$ globulin is necessary for d-limonene promotion of male rat kidney tumors, Cancer Res., 51, 3512, 1991.

121. Dietrich, D. R. and Swenberg, J. A., Preneoplastic lesions in rodent kidney induced spontaneously or by non-genotoxic agents: predictive nature and comparison to lesions induced by genotoxic carcinogens, Mutat. Res., 248, 239, 1991.

122. Slaga, T., Cellular proliferation in multistage carcinogenesis, Proc. Int. Symp. Cell Proliferation and Chemical Carcinogenesis, NIEHS, January, 14-16, 1992.

123. Takasaki, Y., Deng, J.-S., and Tan, E. M., A nuclear antigen associated with cell proliferation and blast transformation, J. Exp. Med., 154, 1899, 1981. 
124. Takasaki, Y., Robinson, W. A., and Tan, E. M., Proliferating cell nuclear antigen in blast crisis cells of patients with chronic myeloid leukemia, J. Natl. Cancer Inst., 73(3), 655, 1984.

125. Foley, J. F., Tuck, P. D., Ton, T.-V. T., Frost, M., Kari, F., Anderson, M. W., and Marompot, R. R., Inhalation exposure to a hepatocarcinogenic concentration of methylene chloride does not induce sustained replicative DNA synthesis in hepatocytes of female B6C3F1 mice, Environ. Health Perspect., in press.

126. Dietrich, D. R., Candrian, R., Marsman, D. S., Popp, J. A., Kaufmann, W. K., and Swenberg, J. A., in preparation.

127. Greenwell, A., Foley, J. F., and Maronpot, R. R., An enhanced method for immunohistochemical staining of proliferating cell nuclear antigen in archival rodent tissues, Cancer Lett., 59, 251, 1991.

128. Foley, J. F., Dietrich, D. R., Swemberg, J. A., and Maronpot, R. R., Detection and evaluation of proliferating cell nuclear antigen (PCNA) in rat tissue by an improved immunohistochemical procedure, $J$. Histotechnol., 14(4), 237, 1991.

129. Robbins, B. A., de la Vega, D., Ogata, K., Tan, E. M., and Nakamura, R. M., Immunohistochemical detection of proliferating cell nuclear antigen in solid malignancies, Arch. Pathol. Lab. Med., 111, 841,1987

130. Garcia, R. L., Coltrera, M. D., and Gown, A. M., Analysis of proliferative grade using anti-PCNA/cyclin monoclonal antibodies in fixed, embedded tissues, Am. J. Pathol., 134, 733, 1989.

131. Thaete, L. G., Ahnen, D. J., and Malkinson, A. M., Proliferating cell nuclear antigen (PCNA/cyclin) immunocytochemistry as a labeling index in mouse lung tissues, Cell Tissue Res., 256, 167, 1989.

132. Dietrich, D. R., Marsman, D. S., Popp, J. A., and Swenberg, J. A., Retrospecitve assessment of liver cell proliferation: Comparison of two proliferation markers, PCNA and tritated thymidine, Toxicologist, 12, 1007, 1992.

133. Dietrich, D. R. and Curtis, L. R., unpublished results.

1.34. Woosley, J. T. and Dietrich, D. R., J. Cutan. Pathol., in press.

135. Woosley, J. T. and Dietrich, D. R., Prognostic significance of PCNA grade in malignant melanoma, $J$. Cutum. Puthol., 19, 557, 1992.

136. Takahashi, H., Strutton, G. M., and Parsons, P. G., Determination of proliferating fractions in malignant melanomas by anti-PCNA/cyclin monoclonal antibody, Histopathology, 18, 221, 1991.

137. van Dierendonck, J. H., Wijsman, J. H., Keijzer, R., van de Velde, C. J. H., and Cornelisse, C. J., Cell-cycle related staining patterns of anti-proliferating cell nuclear antigen monoclonal antibodies, $\mathrm{Am}$. J. Pathol., 1.38(5), 1165, 1991.

138. Rowlands, D. C., Brown, H. E., Barber, P. C., and Jones, E. L., The effect of tissue fixation on immunostaining for proliferating cell nuclear antigen with the monoclonal antibody PC10, J. Pathol., 165, $356,1991$.

139. Foley, J., Ton, T., Maronpot, R. R., Butterworth, B., and Goldsworthy, T. L., Proliferating cell nuclear antigen (PCNA): comparison to tritiated thymidine $\left(\left[{ }^{3} \mathrm{H}\right]-\mathrm{Tdr}\right)$ as a marker of proliferating hepatocytes in rats, Environ. Health Perspect., in press.

140. Nakamura, J., Dietrich, D. R., and Swenberg, J. A., Age-related changes in cell proliferation in rat liver and kidney, Toxicologist, 12, 1014, 1992.

141. Nakamura, J., Dietrich, D. R., Schoonhaven, R., and Swenberg, J. A., In preparation.

142. Shi, S.-R., Key, M. E., and Kalra, K. L., Antigen retrieval in formalin-fixed, paraffin-embedded tissues: an enhancement method for immunohistochemical staining based on microwave oven heating of tissue sections, J. Histochem. Cytochem., 39(6), 741, 1991.

143. Yu, C. C.-W., Hall, P. A., Fletcher, C. D. M., Camplejohn, R. S., Waseem, N. H. W., Lane, D. P., and Levison, D. A., Haemangiopericytomas: the prognostic value of immunohistochemical staining with a monoclonal antibody to proliferating cell nuclear antigen (PCNA), Histopathology, 19, 29, 1991.

144. Greenwell, A., Foley, J. F., and Maronpot, R. R., Proliferating cell nuclear antigen immunohistochemistry: an enhanced method for archival rodent tissue, Toxicologist, 12, 1008, 1992.

145. Maier, P., Schawalder, H., and Elsner, J., Single cell analysis in toxicity testing: the mitogenic activity of thioacetamide in cultured rat hepatocytes analyzed by DNA/protein flow cytometry, Arch. Toxicol., 65, 454, 1991.

146. Maier, P., Kränzlin, R., and Fasciati, R., Identification and characterization of aneuploidy-inducing agents by DNA-protein flow cytometry in V79 chinese hamster cells, Toxicol. Methods, in press.

147. Styles, J., Measurement of ploidy and cell proliferation in the rodent liver, Proc. Int. Symp. Cell Proliferation and Chemical Carcinogenesis, NIEHS, January, 14-16, 1992.

148. Hall, P. A. and Levison, D. A., Review: assessment of cell proliferation in histological material, J. Clin. Pathol., 43, 184, 1990.

149. Hedley, D. W., Friedlander, M. L., Taylor, I. W., Rugg, C. A., and Musgrove, E. A., Method for analysis of cellular DNA content of paraffin-embedded pathological material using flow cytometry, $J$. Histochem. Cytochem., 31(11), 1333, 1983.

150. Hedley, D. W., Flow cytometry using paraffinembedded tissue: five years on, Cytometry, 10, 229, 1989.

151. Vindelov, L. L., Christensen, I. J., and Nissen, N. I., A detergent-trypsin method for the preparation of nuclei for flow cytometric DNA analysis, Cytometry, 3(5), 323, 1983.

152. Woods, A. L., Hall, P. A., Shepherd, N. A., Hanby, A. M., Waseem, N. H., Lane, D. P., and Levison, D. A., The assessment of the proliferating cell nu- 
clear antigen (PCNA) immunostaining in primary gastrointestinal lymphomas and its relationship to histological grade, $S+G 2+M$ phase fraction (flow cytometric analysis) and prognosis, Histopathology, 19, $21,1991$.

153. Jain, S., Filipe, M. I., Hall, P. A., Lane, D. P., and Levison, D. A., Prognostic value of proliferating cell nuclear antigen in gastric carcinomas, J. Clin. Pathol., 44, 655, 1991.

154. Kamel, O. W., LeBrun, D. P., Davis, R. E., Gerry, G. J., and Warnke, R. A., Growth fraction estimation of malignant lymphomas in formalin-fixed paraffin embedded tissue using anti-PCNA/cyclin 19A2, Am. J. Pathol., 138(6), 1472, 1991.

155. Scott, R. J., Hall, P. A., Haldane, J. S., Van Noorden, S., Price, Y., Lane, D. P., and Wright, N. A., A comparison of immunohistochemical markers of cell proliferation with experimentally determined growth fraction, J. Pathol., 165, 173, 1991.

156. Sarraf, C. E., McCormick, C. S. F., Brown, G. R., Price, Y. E., Hall, P. A., Lane, D. P., and Alison, M. R., Proliferating cell nuclear antigen immunolocalization in gastro-intestinal epithelia, Digestion, $50,85,1991$.

157. Paganelli, G. M., Biasco, G., Santucci, R., Brandi, G., Di Febo, G., Miglioli, M., and Barbara, L., Labeling patterns of bromodeoxyuridine and PCNA in human rectal biopsies, Proc. Am. Assoc. Cancer Res., 33, 222, 1992.

158. Eldridge, S. R., Lyght, O., Butterworth, B. E., and Goldsworthy, T. L., Comparison of proliferating cell nuclear antigen and bromodeoxyuridine for measurements of hepatocellular proliferation in mice and rats, Proc. Am. Assoc. Cancer Res., 33, 868, 1992.

159. Eldridge, S. R., Butterworth, B. E., and Goldsworthy, T. L., Proliferating cell nuclear antigen (PCNA): a marker for hepatocellular proliferation in rodents, Environ. Health Perspect., in press.

160. Louis, D. N., Edgerton, S., Thor, A. D., and Hedley-Whyte, E. T., Proliferating cell nuclear antigen and $\mathrm{Ki}-67$ immunohistochemistry in brain tumors: a comparative study, Acta Neuropathol., 81, 675,1991 .

161. Wilcox, D. K. and Bertram, T. A., Colonic epithelial cell proliferation in a rat model of carcinogenesis induced by a nongenotoxin, Toxicologist, 12, 1020, 1992.

162. Ahnen, D. J., Yoshitake, K., Kinoshita, K., and Brown, W., Proliferating cell nuclear antigen expression is a relaible marker of the proliferative compartment in the rat colon, Gastroenterology, 92, 1291, 1987.

163. Goldsworthy, T. L., Dunn, C. S., and Popp, J. A., Dose effects of bromodeoxyuridine (BrdU) on rodent hepatocyte proliferation measurements, Toxicologist, 12, 265, 1992.

164. Weghorst, C. M., Henneman, J. R., and Ward, J. M., Dose response of hepatic and renal DNA synthetic rates to continuous exposure of bromode- oxyuridine (BrdU) via slow-release pellets or osmotic minipumps in male $\mathrm{B} 6 \mathrm{C} 3 \mathrm{Fl}$ mice, J. Histochem. Cytochem., 39, 177, 1991.

165. Hilsenbeck, S. G., Clark, G. M., and McGuire, W. L., Why do so many promising prognostic factors fail to pan out?, Proc. Am. Assoc. Cancer Res., 33, 1211,1992

166. Vilor, M., Khalek, Y., Sorrentino, J., Brown, M., and Herrera, L., Uptake of proliferating cell nuclear antigen as a prognostic factor in soft-tissue sarcomas, Proc. Am. Assoc. Cancer Res., 33, 1210, 1992.

167. Thomas, H., Nasim, M. M., Sarraf, C. E., Alison, M. R., Lambert, H. E., and Price, P. M., Quantitation of proliferation in ovarian cancer by proliferating cell nuclear antigen (PCNA) immunostaining, Proc. Am. Assoc. Cancer Res., 33, 1554, 1992.

168. Robins, P., Jones, C. J., Biggerstaff, M., Lindahl, T., and Wood, R. D., Complementation of DNA repair in xeroderma pigmentosum group A cell extracts by a protein with affinity for damaged DNA, EMBO J., 10(12), 3913, 1991.

169. Kawakita, N., Seki, S., Sakaguchi, H., Yanai, A., Kuroki, T., Mizoguchi, Y., Kobayashi, K., and Monna, T., Analysis of proliferating hepatocytes using a monoclonal antibody against proliferating cell nuclear antigen/cyclin in embedded tissues from varous liver diseases fixed in formaldehyde, Am. J. Pathol, 140(2), 513, 1992.

170. Tereda, T. and Nakunama, Y., Cell kinetic analyses and expression of carcinoembryonic antigen, carbohydrate antigen 19-9 and DU-PAN-2 in hyperplastic, preneoplastic and neoplastic lesions of intrahepatic bile ducts in livers with hepatoliths, Virchow's Arch. A Pathol. Anat., 420, 327, 1992.

171. Rao, V. V. N. G., Schnittger, S., and Hansmann, I., Chromosomal localization of the human proliferating cell nuclear antigen (PCNA) gene to or close to $20 \mathrm{pl} 2$ by in situ hybridization, Cytogenet. Cell Genet., 56, 169, 1991.

172. Ku, D.-H., Travali, S., Calabretta, B., Huebner, $\mathbf{K}$., and Baserga, $\mathbb{R}$., Human gene for proliferating cell nuclear antigen has pseudogenes and localizes to chromosome 20, Somat. Cell Mol. Genet., 15(4), $297,1989$.

173. Suzuka, I., Hata, S., Matsuoka, M., Kosugi, S., and Hashimoto, J., Highly conserved structure of proliferating cell nulcear antigen (DNA polymerase $\delta$ auxiliary protein) gene in plants, Eur. J. Biochem., $195,571,1991$.

174. Kodama, H., Ito, M., Ohnishi, N., Suzuka, I., and Komamine, A., Molecular cloning of the gene for plant proliferating cell nuclear antigen and expression of this gene during the cell cycle in synchronized cultures of Cantharanthus roseus cells, Eur. J. Biochem., 197, 495, 1991.

175. Coverley, D., Kenny, M. K., Munn, M., Rupp, W. D., Lane, D. P., and Wood, R. D., Requirement for the replication protein SSB in human DNA excision repair, Naturc, 349, 538, 1991. 
176. Huang, J.-C., Svoboda, D. L., Reardon, J. T., and Sancar, A., Human nucleotide excision nuclease removes thymine dimers from DNA by incising the 22nd phosphodiester bond $5^{\prime}$ and the 6th phosphodiester bond $3^{\prime}$ to the photodimer, Proc. Natl. Acad. Sci. U.S.A., 89, 3664, 1992.

177. Sarnow, P., Ho, Y. S., Williams, J., and Levine, A. J., Adenovirus E1b-58kd tumor antigen and SV40 large tumor antigen are physically associated with the same $54 \mathrm{kd}$ cellular protein in transformed cells, Cell, 28, 387, 1982.

178. Whyte, P., Buchkovich, K. J., Horowitz, J. M., Friend, S. H., Raybuck, M., Weinberg, R. A., and Harlow, E., Association between an oncogene and an anti-oncogene: the adenovirus E1A proteins bind to the retinoblastoma gene product, Nature, 334, $124,1988$.

179. Taya, Y., Yasuda, H., Kamijo, M., Nakaya, K., Nakamura, Y., Ohba, Y., and Nishimura, S., In vitro phosphorylation of the tumor suppressor gene $\mathrm{Rb}$ protein by mitosis-specific histone $\mathrm{Hl}$ kinase, Biochem. Biophys. Res. Commun., 164(1), 580, 1989.

180. Eliyahu, D., Michalovitz, D., Eliyahu, S., PinhasiKimhi, O., and Oren, M., Wild-type p53 can inhibit oncogene-mediated focus formation, Proc. Natl. Acad. Sci. U.S.A., 86, 8763, 1989. 